\title{
Process Systems Engineering Studies for the Synthesis of Catalytic Biomass-to-fuels Strategies
}

\author{
Jeehoon Han ${ }^{1}$, S. Murat Sen, Jeremy S. Luterbacher, David Martin Alonso, \\ James A. Dumesic and Christos T. Maravelias ${ }^{2}$ \\ Department of Chemical and Biological Engineering \\ University of Wisconsin-Madison \\ Madison, WI 53706, USA
}

\begin{abstract}
The goal of this paper is to show how chemical process synthesis and analysis studies can be coupled with experimental heterogeneous catalysis studies to identify promising research directions for the development of strategies for the production of renewable fuels. We study five catalytic biomass-to-fuels strategies that rely on production of platform chemicals, such as levulinic acid and fermentable sugars. We first integrate catalytic conversion subsystems with separation subsystems to generate complete conversion strategies, and we then develop the corresponding process simulation models based on experimental results. Our analyses suggest that catalytic biomass-to-fuel conversion strategies could become economically competitive alternatives to current biofuel production approaches as a result of iterative experimental and computational efforts.
\end{abstract}

${ }^{1}$ Current address: School of Chemical Engineering, Chonbuk National University, Jeonju 561-756, Korea.

${ }^{2}$ Corresponding author: Tel.: +1 608265 9026; fax: +1 608262 5435. E-mail address: maravelias@wisc.edu 


\section{Introduction}

Driven by energy challenges facing the world today, fundamental research has focused on development of technologies that offer sustainable and affordable alternatives to meet growing global energy demand while addressing environmental and social issues (Farrell et al., 2006; Hill et al., 2006; Dale, 2008). Lignocellulosic biomass offers a promising alternative to satisfy future energy demand because it is a widely abundant and a potentially carbon neutral source for producing a wide range of fuels and fuel additives (Chheda et al., 2007; Demirbas, 2007; Alonso et al., 2012; Wettstein et al., 2012). Lignocellulosic biomass primarily consists of three polymeric components: cellulose ( $\mathrm{C}_{6}$-sugars), hemicellulose (mainly $\mathrm{C}_{5}$-sugars) and lignin. In the last few decades, a wide range of conversion technologies have been developed for the effective utilization of each biomass fraction (Huber et al., 2006; Bozell and Petersen, 2010; Naik et al., 2010; Bond et al., 2014).

The major challenge in the conversion of biomass to liquid fuels is the effective extraction of the sugars in biomass (Mosier et al., 2005). To address this challenge, a common approach is to fractionate biomass into its components using pretreatment, including dilute acid (Humbird et al., 2011), lime (Eggeman and Elander, 2005), hot water (Tao et al., 2011), ionic liquid (Klein-Marcuschamer et al., 2011; Sen et al., 2012b), alkaline hydrogen peroxide (Banerjee et al., 2011) and ammonia fiber expansion (Sendich et al., 2008; Bals et al., 2011). Following the pretreatment, lignin is typically used for heat and power generation via combustion (Holladay et al., 2007), while the hemicellulose and cellulose fractions can be converted to various fuels and fuel additives typically via three major routes: biochemical, thermochemical and catalytic (Anex et al., 2010). The biochemical conversion strategies, primarily based on enzymatic hydrolysis and microbial fermentation, (Gnansounou and Dauriat, 2010) offer high overall biomass-tofuel yields (50-55 mol\%), but require high enzyme costs, $15-20 \%$ of the total production cost (CondeMejía et al., 2013). Thermochemical conversion technologies, such as pyrolysis and gasification, operate at high temperatures (pyrolysis: 573-973 K, gasification: >1100 K), thereby resulting in high energy requirements (Lange, 2007). Catalytic conversion strategies can offer advantages such as less expensive processing with high selectivity and carbon yield at milder processing conditions (Alonso et al., 2010).

Although the technologies outlined above have been demonstrated at laboratory scale, process synthesis and technoeconomic evaluation are critical steps for translating these technologies into economically attractive processes (Aden and Foust, 2009; Grossmann and Guillén-Gosálbez, 2010; Pokoo-Aikins et al., 2010; Floudas et al., 2012; Stuart and El-Halwagi, 2012; Daoutidis et al., 2013; Yuan et al., 2013). Several researchers have developed methods for the development of various biorefinery configurations based on specific conversion technologies (Sammons Jr et al., 2008; Klein-Marcuschamer et al., 2010; Kokossis and Yang, 2010; Martín and Grossmann, 2011; Pham and El-Halwagi, 2012; You et al., 2012; Baliban et al., 2013; Gebreslassie et al., 2013; Kelloway and Daoutidis, 2013; Kim et al., 2013; Gong and You, 2014). In addition, several studies have focused on the technoeconomic analysis of biochemical (Cardona and Sánchez, 2007; Kazi et al., 2010) and thermochemical (Mohan et al., 2006; Swanson et al., 
2010; Wright et al., 2010) strategies. However, there are not many systems-level studies for catalytic biomass-to-fuels conversion technologies.

Accordingly, in this paper we present a series of studies for the synthesis and analysis of five catalytic biomass-to-fuels conversion strategies that rely on production of platform chemicals such as levulinic acid (Alonso et al., 2011; Braden et al., 2011; Gürbüz et al., 2011; Alonso et al., 2013) and fermentable sugars (Luterbacher et al., 2014). In addition to evaluating the economic potential of these strategies, we also aim to show how systems-level studies can be used in parallel with heterogeneous catalysis studies to identify the major technological bottlenecks and cost drivers, thereby pointing the way to new research directions and guide experimental research. Towards this aim, we outline our joint efforts over a period of five years (2010-2014). While many of the analyses in this paper have appeared separately in the literature, our goal here is to illustrate how the synthesis and analysis of integrated processes can led to basic science developments which in turn were used for updated analyses, ultimately leading to iterative improvements. We hope that this exposition will illustrate the synergies between process systems engineering and heterogeneous catalysis and inspire similar research efforts.

The paper is structured as follows: in sections 2 and 3, we describe the chemistry of the systems we study, and present five biomass-to-fuels strategies synthesized based on distinct catalytic technologies. Our chemical process design studies are summarized in section 4. Section 5 discusses energy efficiency calculations, a topic often overlooked despite its paramount importance (since our goal is to replace fossil fuels). The results of the technoeconomic evaluation are presented in section 6. Finally, in section 7 we discuss a series of alternatives as well as the impact of uncertainty in a subset of parameters.

\section{Cellulose Conversion Strategies}

We first explore different options for the conversion of the cellulose fraction of biomass into liquid hydrocarbon fuels (butene oligomers) via production of levulinic acid (LA) and formic acid (FA) intermediates from the sulfuric acid (SA) catalyzed deconstruction of cellulose (Fig. 1). The biomass is first pretreated using dilute acid to remove the hemicellulose fraction, then filtered. The hemicellulose is converted to solubilized xylose and subsequently used to produce heat and generate electricity, while the insoluble cellulose is further converted to hydrocarbons. Following cellulose deconstruction, the main challenge is to extract biomass-derived intermediates (such as LA, FA and $\gamma$-valerolactone (GVL)) that are at low concentrations from the SA-containing aqueous phase. Separation of SA from the intermediates is also critical to prevent its negative effects in downstream catalytic conversion processes. To this end, we developed strategies that effectively recover biomass-derived intermediates while recycling almost $100 \%$ of the SA back to the cellulose deconstruction step.

\subsection{Chemistry}

Levulinic acid (LA) has been identified as a versatile platform molecule for production of liquid hydrocarbon fuels, fuel additives, as well as a variety of chemicals (Bozell and Petersen, 2010). Using an aqueous SA solution $(0.5 \mathrm{M})$ as a catalyst, the cellulose fraction of biomass can be deconstructed to LA 
and FA in a batch reactor at $473 \mathrm{~K}$ and 16 bar with a high yield (55 mol\%), while the remaining cellulose is degraded to form humins (Serrano-Ruiz et al., 2010). Following cellulose deconstruction, the LA can be converted to GVL with near quantitative yields over a bimetallic catalyst ( $\operatorname{RuRe}(3: 4) / \mathrm{C}$ (Braden et al., 2011) or RuSn(1:4)/C (Alonso et al., 2011) using internal hydrogen released from FA decomposition, at $493 \mathrm{~K}$ and 36 bar. The GVL production from LA partially reduces the oxygen content and increases the energy density while keeping sufficient functionality to produce the final fuel compounds. Braden and coworkers (Braden et al., 2011) showed that the presence of Re in the catalyst is crucial to maintain catalytic stability for GVL production in the presence of SA. Alternatively, a less expensive catalyst $(\mathrm{RuSn}(1: 4) / \mathrm{C})$ can be used if the biomass-derived intermediates are extracted from the SA-containing aqueous solution prior to GVL production (Alonso et al., 2011). To eliminate the use of external solvents, Dumesic and coworkers (Gürbüz et al., 2011) suggested that LA and FA can be converted to their esters using butene, a product of the process, in a reactive extraction unit where the esters spontaneously separate from the SA containing aqueous solution by forming their own organic phase, while any remaining LA and FA are also extracted in the ester phase. In the reactive extraction unit, $60 \mathrm{~mol} \%$ of the LA can be converted to sec-butyl levulinate (BL) and $49 \mathrm{~mol} \%$ of the FA can be converted to sec-butyl formate (BF) at $353 \mathrm{~K}$ and 35 bar. Then, the BL and unconverted LA can be reduced to GVL with near quantitative yields over a dual-catalyst bed system (10 wt\% Pd/C and $5 \mathrm{wt} \% \mathrm{Ru} / \mathrm{C}$ ) at $443 \mathrm{~K}$ and 35 bar (Gürbüz et al., 2011). In the last step, GVL can be converted to a mixture of larger alkene oligomers (liquid hydrocarbon fuels) using a dual reactor conversion approach. First, the ring opening of GVL produces an isomeric mixture of unsaturated pentenoic acids, which are decarboxylated over silica alumina $\left(\mathrm{SiO}_{2} / \mathrm{Al}_{2} \mathrm{O}_{3}\right)$ forming a mixture of butene isomers and $\mathrm{CO}_{2}$. Finally, butene isomers can be oligomerized into larger molecular weight alkene species using a solid acid catalyst (Amberlyst-70) with near quantitative yields, leading to mixtures of gasoline and jet fuel range alkenes (Bond et al., 2010). As shown in Fig. 1, the "potential" cellulose-to-butene yield is found to be $\sim 54 \mathrm{~mol} \%$. Here, "potential yield" is meant to be the maximum achievable overall yield if there would be no loss in separation subsystems.

\subsection{Process Synthesis}

As mentioned earlier, the main challenge for the SA-catalyzed conversion of cellulose is the separation of biomass-derived intermediates from the SA-containing aqueous solution. To overcome this challenge, we synthesized three strategies that effectively extract intermediates from the aqueous solution and convert them into liquid hydrocarbon fuels. The details of the design and analysis of these strategies are presented in sections 4 to 6, while the major assumptions are given in Table S2 in the supplementary content.

\subsubsection{Strategy A}

Strategy A is based on the catalytic system that uses RuRe/C catalyst for reduction of LA to GVL using the internal hydrogen produced from FA decomposition in the presence of SA (Braden et al., 2011) and it is shown in Fig. 2. To separate GVL from the SA solution, which was the major challenge in this strategy, we developed a multi-stage extraction process that can separate $98 \%$ of the GVL from the aqueous solution using butyl acetate (BA) as a solvent by taking advantage of the high partition coefficient of BA for GVL (Sen et al., 2012d). The modeling of the extraction unit was based on experimentally determined 
partition coefficients. Using the multi-stage extraction, 97\% of the SA is also recovered in the aqueous phase and recycled back to the cellulose deconstruction step. Following the extraction, GVL is separated from the BA solvent in a distillation unit. However, distillation of GVL and BA is an energy-intensive operation due to evaporation of the abundant component, BA solvent, since BA has a lower boiling point than GVL. By distillation, 99\% of the BA (distillate) is removed from GVL and recycled to the extraction unit, while GVL is converted to butene, and subsequently to butene oligomers. According to our technoeconomic analysis, the results of which will be presented in more detail in section 6, strategy A requires a capital investment of $\$ 486$ million and results in a minimum selling price (MSP), which is the price that leads to zero net present value, of $\$ 9.36$ per gallon of gasoline equivalent (GGE) for butene oligomers. Also, the overall biomass-to-fuel yield is found to be $\sim 21 \mathrm{C} \mathrm{mol \%}$. Potential drawbacks of strategy A are (i) the use of an external solvent, (ii) energy intensive distillation due to evaporation of the BA solvent, and (iii) high catalyst regeneration cost, especially for GVL production.

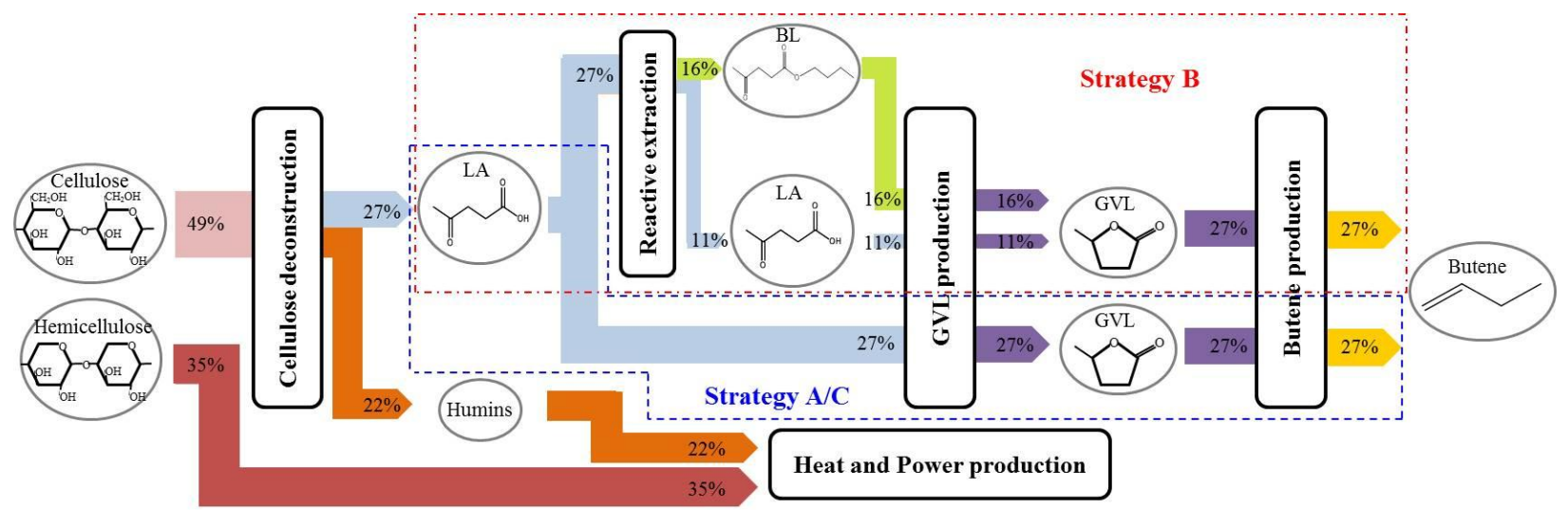

Fig. 1 Chemistry and reaction yields $(\mathrm{mol} \%)$ for conversion of cellulose into butene.

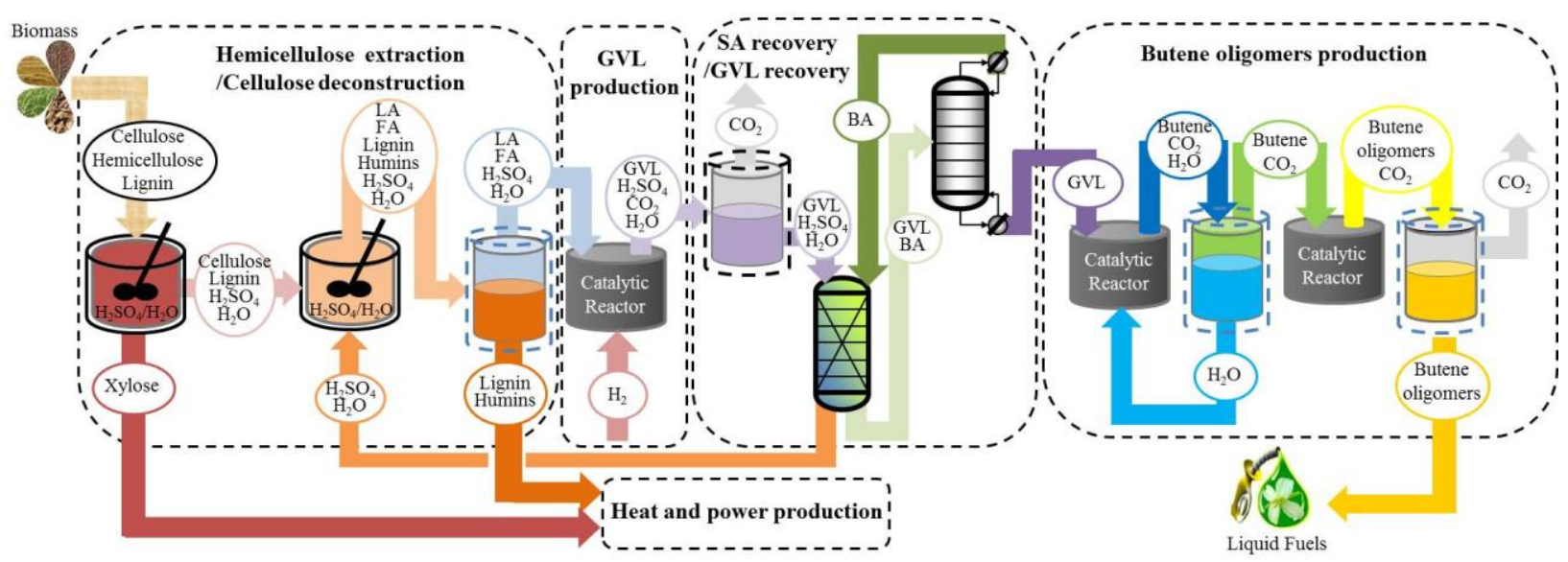

Fig. 2 Process flow diagram of strategy A (use of butyl acetate solvent for extraction of GVL from the SA containing aqueous solution).

\subsubsection{Strategy $B$}

To address the shortcomings identified by our analysis, namely, the external solvent use and energy intensive separation steps, we synthesized strategy B based on the reactive extraction process that 
converts LA and FA intermediates to their esters (sec-butyl levulinate (BL) and sec-butyl formate (BF), respectively) using butene, a product of the process (Gürbüz et al., 2011). The esters spontaneously separate from the SA aqueous solution, thereby extracting any remaining LA and FA (Fig. 3). Experimental studies showed that a concentrated stream of intermediates is needed for this reactive extraction process (Gürbüz et al., 2011). To address this issue, we modified the original process configuration by adding an evaporation unit before the reactive extraction, and most of the water is removed by evaporation from the aqueous solution (Sen et al., 2012c). In the reactive extraction unit, the organic phase containing BL and BF esters spontaneously extracts 53\% of the unconverted LA and 50\% of the FA from the aqueous phase (Sen et al., 2012c). Then, the esters and the unconverted LA and FA are converted to GVL and hydrogen, respectively over a dual-catalyst-bed with high yield. The first catalyst bed $(\mathrm{Pd} / \mathrm{C})$ converts FA and $\mathrm{BF}$ to hydrogen, and the second catalyst bed $(\mathrm{Ru} / \mathrm{C})$ converts $\mathrm{LA}$ and $\mathrm{BL}$ to GVL by utilizing the in situ hydrogen generated over the upstream $\mathrm{Pd} / \mathrm{C}$ bed. Our analysis showed that strategy B requires a capital investment of $\$ 485$ million and results in the MSP of $\$ 9.63$ per GGE. Although strategy B eliminates the external solvent use and energy-intensive distillation step, the overall biomass-to-fuels yield is slightly lower ( $20 \mathrm{~mol} \%)$ due to material losses in evaporation and the number of conversion steps. Another major cost driver of strategy B is the high catalyst regeneration cost due to use of $\mathrm{Pd} / \mathrm{C}$ catalyst for hydrogen production.

\subsubsection{Strategy $C$}

Our process analyses indicated that one of the major drawbacks in strategies A and B is the necessity of a SA-tolerant catalyst, which leads to high catalyst regeneration cost. To eliminate the need for an SA tolerant catalyst, we developed strategy $\mathrm{C}$ based on the extraction of the LA using an alkylphenol solvent (2-sec-butyl phenol (SBP)) before the hydrogenation step to convert LA to GVL (Alonso et al., 2011). The use of SBP for extraction is advantageous due to its high boiling point that leads to significant energy and equipment cost savings in a downstream distillation of GVL-SBP compared to GVL-BA distillation in strategy A (Sen et al., 2012a). In addition, the high boiling point of SBP makes extraction at elevated temperatures possible if needed. Also, SBP has a high partition coefficient for LA, and thus almost 100\% of the LA can be extracted from the aqueous solution using SBP after 6 stages of extraction (Sen et al., 2012a). However, only $29 \%$ of the FA, the internal source of hydrogen for LA reduction to GVL, can be extracted since SBP has a low partition coefficient for FA. Therefore, strategy $\mathrm{C}$ requires more make-up hydrogen compared to strategies A and B. Other potential drawbacks of strategy $\mathrm{C}$ are the high solvent cost and energy-intensive (water and FA) evaporation step that in turn reduces revenues from excess electricity sales. Based on our analysis, the capital investment required for strategy $\mathrm{C}$ is $\$ 473$ million, whereas the MSP of butene oligomers and the overall biomass-to-fuel yield are found to be $\$ 9.30$ per GGE and $\sim 21 \mathrm{~mol} \%$, respectively. 


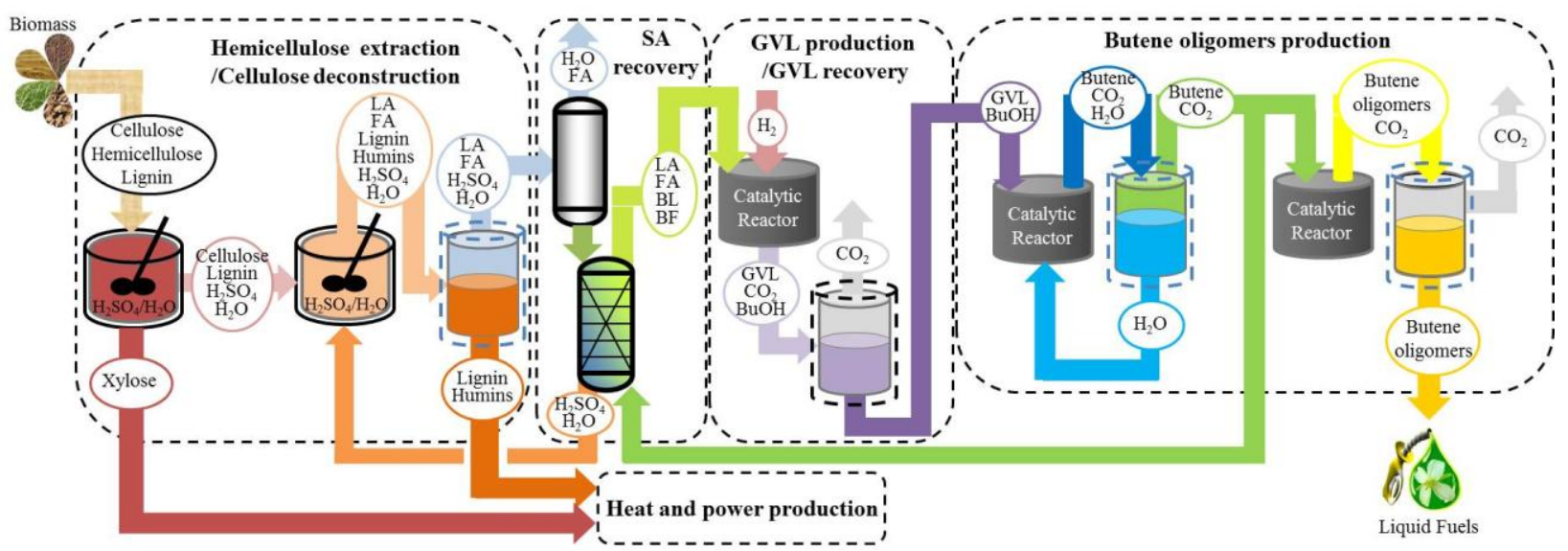

Fig. 3 Process flow diagram of strategy B (use of reactive extraction of biomass-derived intermediates by their esters to spontaneously separate them from the SA containing aqueous solution).

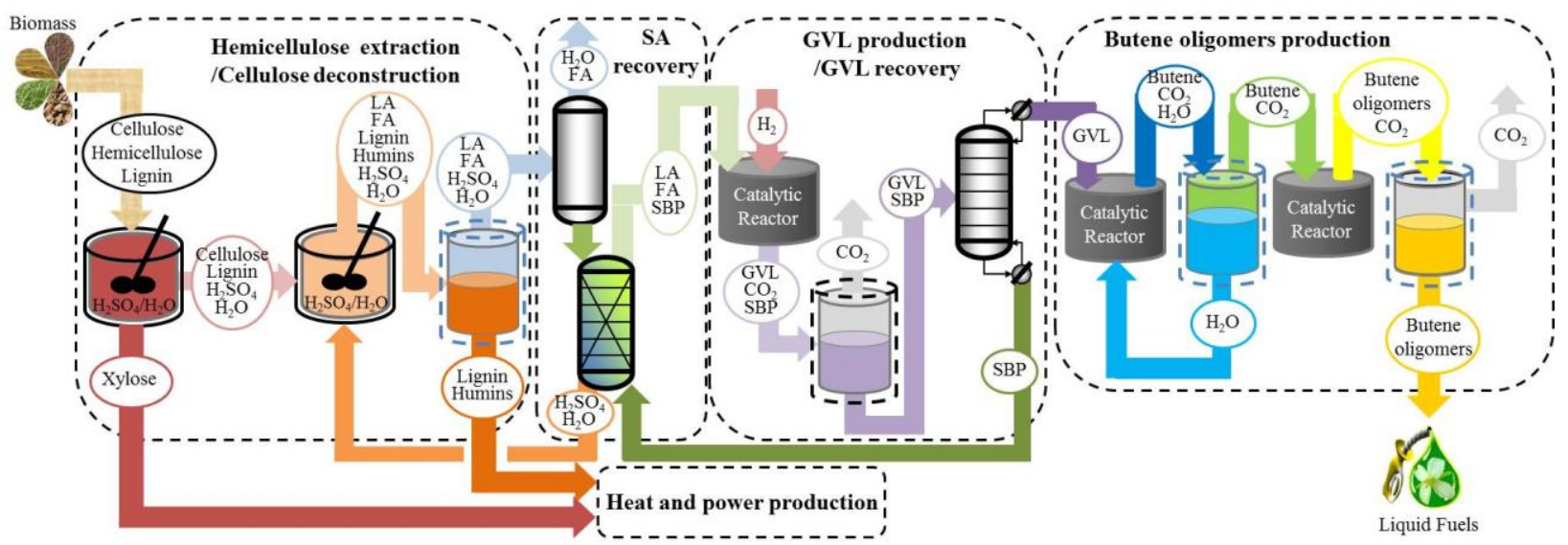

Fig. 4 Process flow diagram of strategy C (use of alkylphenol solvent for extraction of LA and FA from the SA containing aqueous solution).

\section{Simultaneous Cellulose and Hemicellulose Conversion Strategies}

Our systems level studies showed that a major drawback of the strategies presented in Section 2 is their low overall biomass-to-fuels yields, because only the cellulose fraction of lignocellulosic biomass is converted and the revenue from excess electricity sales does not improve the economics significantly. To obtain improved yields, we further explored new alternatives for the simultaneous conversion of cellulose and hemicellulose fractions of biomass into liquid transportation fuels using biomass-derived GVL as a solvent for biomass deconstruction. Using different solvent-to-biomass ratios for biomass deconstruction, we identified two alternatives that rely on the production of different platform intermediates and final products. The first pathway produces LA and furfural that can be converted to GVL and subsequently to butene oligomers (Alonso et al., 2013), while the second pathway, using a higher solvent-to-biomass ratio, leads to non-enzymatic production of sugars that can be fermented to produce ethanol (Luterbacher et al., 2014). 


\subsection{Chemistry}

The first pathway for the conversion of hemicellulose and cellulose mainly relies on three catalytic conversion steps: (i) furfural and LA production from hemicellulose and cellulose hydrolysis/dehydration, respectively, (ii) furfural and LA conversion to GVL, and (iii) production of butene oligomers from GVL (Fig. 5). First, the hemicellulose and cellulose fractions can be converted with high yields into furfural (56 $\mathrm{mol} \%$ ) and LA (61 mol\%), respectively, in a biomass deconstruction reactor at $443 \mathrm{~K}$, containing $16 \mathrm{wt} \%$ biomass and dilute SA catalyst $(0.1 \mathrm{M})$ in GVL/water $(4: 1 \mathrm{wt} / \mathrm{wt})$ solution, while the remaining hemicellulose and cellulose are degraded to form humins (Alonso et al., 2013). Then, furfural and LA can be converted to GVL with $62 \%$ and $99 \%$ molar yields, respectively, over a triple-catalyst bed system $\left(\mathrm{Pt}_{3} \mathrm{Sn} / \mathrm{SiO}_{2}\right.$, Amberlyst-70 and $\mathrm{RuSn}_{4} / \mathrm{C}$ ) in the presence of the GVL solvent (Alonso et al., 2013). The remaining furfural and LA are degraded to form humins. Finally, a solution of GVL that contains $40 \mathrm{wt} \%$ of water can be converted to butene oligomers with near quantitative yield over a dual-catalyst bed system $\left(\mathrm{SiO}_{2} / \mathrm{Al}_{2} \mathrm{O}_{3}\right.$ and Amberlyst-70) (Bond et al., 2010). The "potential" cellulose-to-butene and hemicellulose-to-butene yields are $60 \%$ and $35 \%$, respectively.

As an alternative, the hemicellulose and cellulose fractions of biomass can be converted into ethanol based on the following steps: (i) catalytic conversion of hemicellulose and cellulose to soluble $\mathrm{C}_{5^{-}}$and $\mathrm{C}_{6^{-}}$ sugars, respectively, and (ii) conversion of sugars to ethanol by fermentation (Fig. 6). The $\mathrm{C}_{5^{-}}$and $\mathrm{C}_{6^{-}}$ sugars can be first produced from the catalytic conversion of hemicellulose and cellulose in a two-stage reaction system in GVL/water (4:1 wt/wt) solution at a biomass loading of $7 \mathrm{wt} \%$ (Luterbacher et al., 2014). The first stage converts most of the hemicellulose to soluble $\mathrm{C}_{5}$-sugars using a low GVL-tobiomass ratio $(4: 1 \mathrm{wt} / \mathrm{wt})$, whereas the second stage converts most of the cellulose to soluble $\mathrm{C}_{6}$-sugars (glucose) using a high GVL-to-biomass ratio $(20: 1 \mathrm{wt} / \mathrm{wt})$. This reaction system leads to complete conversions of hemicellulose and cellulose with high yields of $\mathrm{C}_{5}$-sugars from hemicellulose $(70 \mathrm{~mol} \%)$ and $\mathrm{C}_{6}$-sugars from cellulose $(69 \mathrm{~mol} \%)$, whereas the remaining hemicellulose and cellulose are degraded to form furfural, LA, and humins. After reducing the GVL concentration to avoid inhibition of microbial growth the soluble sugars can be then upgraded to $5 \mathrm{wt} \%$ of ethanol with $87 \%$ molar yields over engineered yeast strains (Lau and Dale, 2009; Luterbacher et al., 2014). The "potential" cellulose-toethanol and hemicellulose-to-ethanol yields for this alternative are $60 \%$ and $61 \%$, respectively.

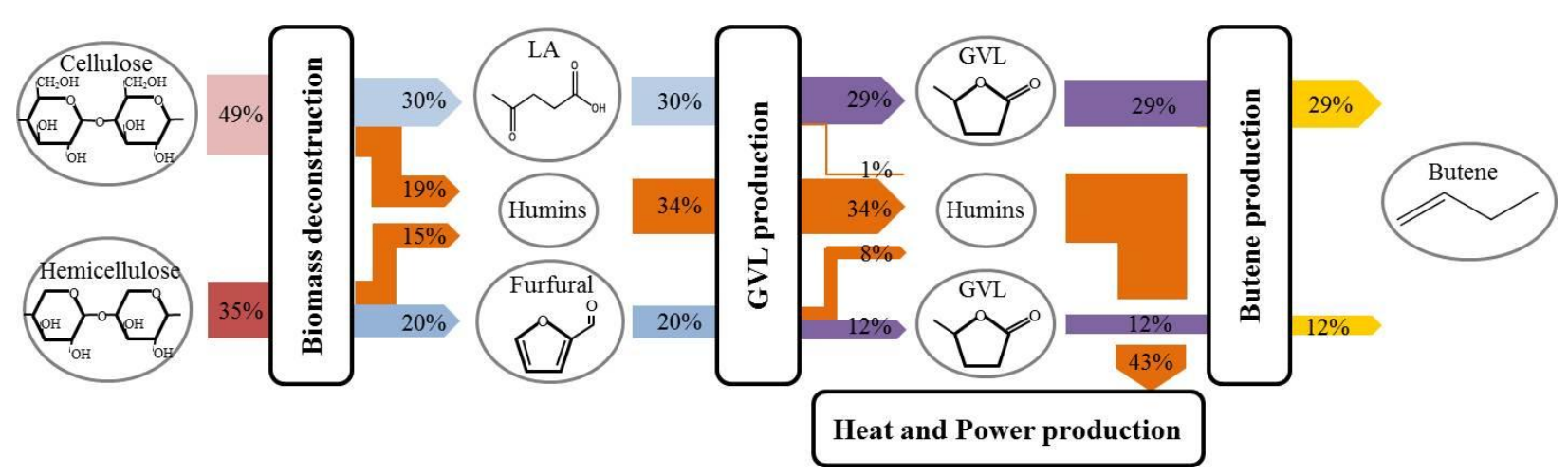

Fig. 5 Chemistry and reaction yields $(\mathrm{mol} \%)$ for simultaneous conversion of hemicellulose and cellulose to butene. 


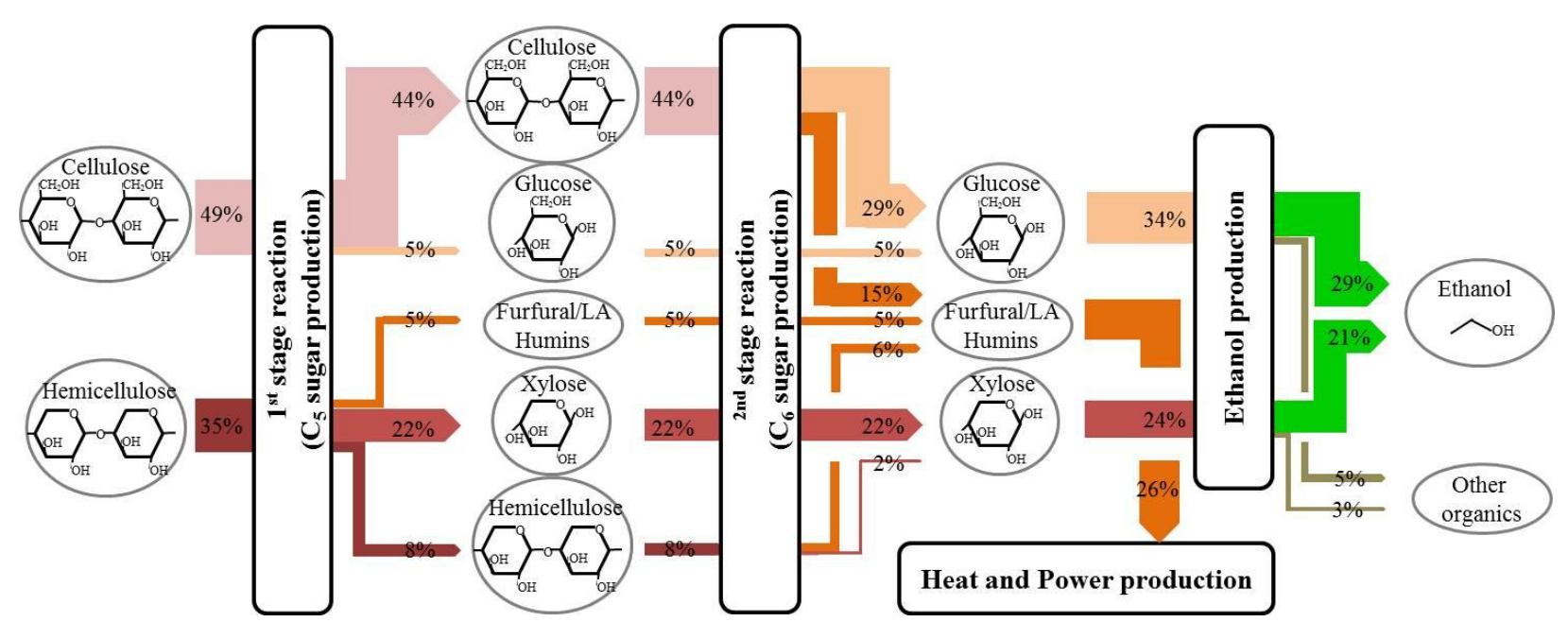

Fig. 6 Chemistry and reaction yields (mol\%) for simultaneous conversion of hemicellulose and cellulose to ethanol.

\subsection{Process Synthesis}

\subsubsection{Strategy $D$}

We developed two strategies ( $\mathrm{D}$ and $\mathrm{E}$ ) for the integrated conversion of cellulose and hemicellulose into liquid fuels. Strategy D, which is shown in Fig. 7, is based on the catalytic pathway that uses GVL as a solvent for deconstruction of the cellulose and hemicellulose fractions to LA and furfural, respectively (Alonso et al., 2013). Then, LA and furfural are converted to GVL and subsequently to butene oligomers as in strategies A-C. The main challenge in strategy D is to separate $\mathrm{GVL}$ from $\mathrm{CO}_{2}$ and biomass residues (lignin and humins) effectively. To address this challenge, we designed a separation subsystem for GVL recovery and integrated this separation subsystem with the catalytic conversion subsystems (Han et al., 2014). Following GVL production, $99 \%$ of the $\mathrm{CO}_{2}$ is first separated from the GVL-rich stream by expansion and $99 \%$ of the GVL is then separated from the biomass residues by evaporation. After evaporation, $96 \%$ of the GVL is recycled back to the biomass deconstruction and the remaining GVL is converted to butene oligomers. The biomass residues recovered after evaporation are used for steam and power generation. Compared to strategies A-C, strategy D offers not only a higher overall biomass-tofuels yield (36 mol\%), but also a significant capital cost saving, because it eliminates the need for a hemicellulose removal step which accounts for up to 20-30\% of the total installed equipment cost (Kazi et al., 2010). On the other hand, a potential drawback of this strategy is the large heating requirement for recovery of GVL. The heating requirement for GVL recovery accounts for 53\% of the total heating requirement of the overall process which corresponds to $73 \%$ of the energy content of biomass residues used for steam production. Although heating requirement of the overall process could be recovered from the combustion of biomass residues, it leads to a reduction in revenues from excess electricity sales. Our technoeconomic analysis showed that strategy D requires a capital investment of \$391 million and results in the MSP of $\$ 5.43$ per GGE. 


\subsubsection{Strategy $E$}

Strategy E is based on the two-stage reaction system for the non-enzymatic production of sugars (Luterbacher et al., 2014). The major challenge in strategy $\mathrm{E}$ is the purification the sugars as well as the recovery of GVL from biomass residues. To overcome these challenges, we designed a separation subsystem for recovery of sugars from the GVL-rich solution using $\mathrm{CO}_{2}$ extraction, as well as a separation subsystem for recovery of the GVL solvent from $\mathrm{CO}_{2}$ and biomass residues (Fig. 8). Following the two-stage sugar production, $99 \%$ of the GVL is separated from the SA-containing aqueous phase after 5 stages of extraction using liquid $\mathrm{CO}_{2}$ with a $\mathrm{CO}_{2}$-to-feed mass ratio of 0.5 (Luterbacher et al., 2014), while $86 \%$ of the sugars remains in the aqueous solution. Ethanol is produced from fermentation of biomass-derived sugars, while the GVL-rich mixture containing $\mathrm{CO}_{2}$ and residues is sent to subsequent separation subsystems to recover $\mathrm{CO}_{2}$ and GVL. To achieve these tasks, the GVL-rich mixture is first sent to a $\mathrm{CO}_{2}$ separation system consisting of five vapor-liquid separators connected in series which undergo an increase in temperature (in the first separator) and reduction in pressure (from the second to the fifth separators). Note that the $\mathrm{CO}_{2}$ separation system is shown with a single flash unit and a compressor in Fig. 8 for simplicity. Using this system, $99 \%$ of the $\mathrm{CO}_{2}$ is separated from the GVL-rich stream and recompressed before being recycled to the extraction unit. Following the $\mathrm{CO}_{2}$ separation, 33\% of the GVL-rich stream is vaporized to separate GVL from biomass residues, and the vapor stream containing most of the GVL is then recycled back to the biomass deconstruction step. 33\% of the GVL-rich stream is recycled only after catalytic conversion of $\mathrm{LA}$ to $\mathrm{GVL}$ in a $\mathrm{H}_{2}$-rich environment over $\mathrm{RuSn}_{4} / \mathrm{C}$ catalysts, and the remaining stream is recycled directly to the biomass deconstruction step. As a result, strategy $\mathrm{E}$ leads to a higher hemicellulose-to-fuels (61 mol\%) yield than strategy D (35 mol\%). Compared to strategies A-D, strategy E offers not only a higher overall biomass-to-fuel yield (46 C mol\%), but also great flexibility to produce a wide range of fuels, fuels additives, and chemicals from sugars. Our technoeconomic analysis showed that strategy E requires a capital investment of $\$ 517$ million and results in the MSP of $\$ 4.99$ per GGE. However, this strategy has a larger heating requirement for recovery of GVL compared to strategy $\mathrm{D}$, because it requires a higher solvent-to-biomass ratio (14:1 wt $\%)$ than strategy $\mathrm{D}(4: 1 \mathrm{wt} \%)$. However, the heating requirement can be reduced significantly through heat integration (e.g., integration of cooling duty for the two-stage reaction with the heating duty for the GVL evaporation) as discussed in section 5.

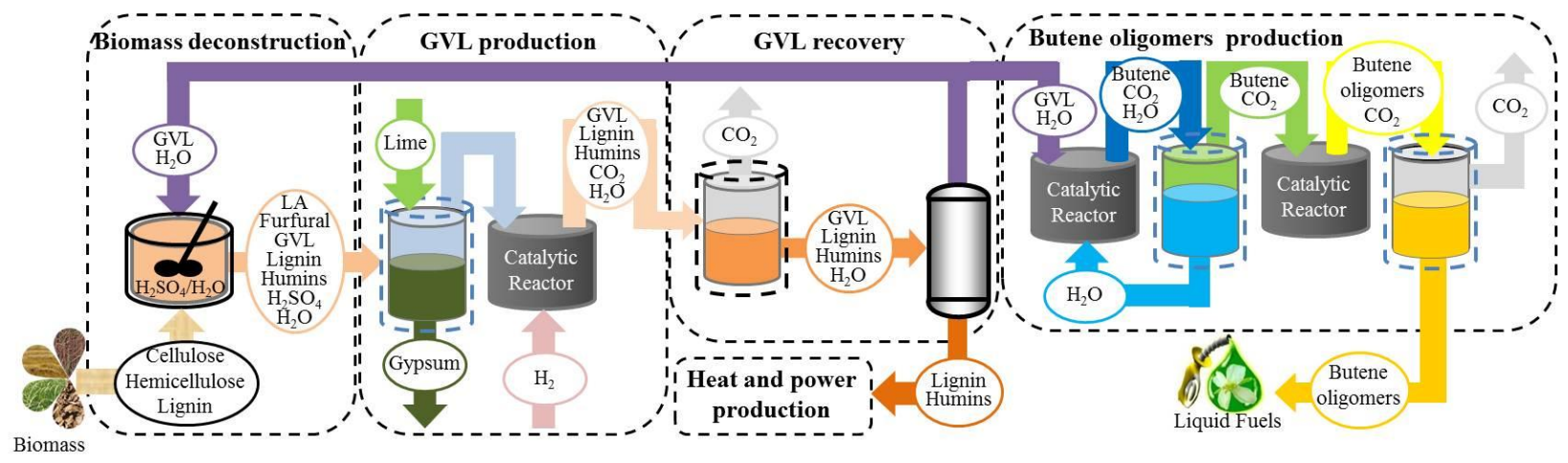


Fig. 7 Process flow diagram of strategy D (simultaneous conversion of hemicellulose and cellulose into butene oligomers).

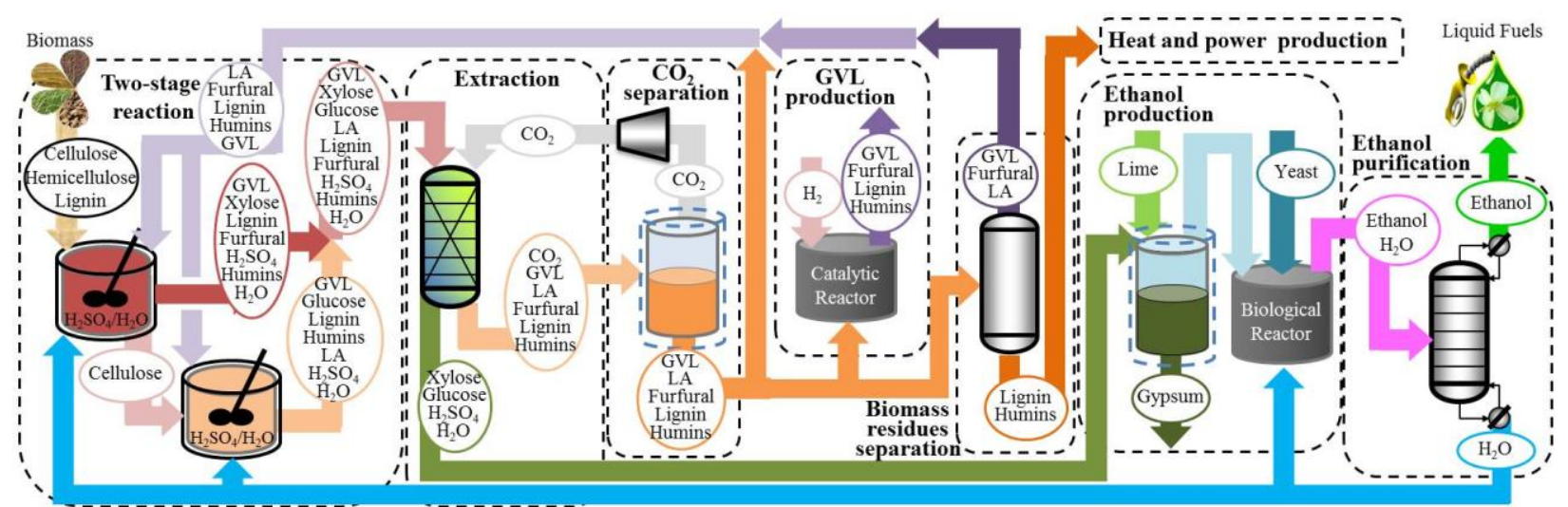

Fig. 8 Process flow diagram of strategy E (simultaneous conversion of hemicellulose and cellulose into ethanol).

\section{Process Design}

\subsection{Design Basis and Assumptions}

To compare our strategies with the benchmark lignocellulosic ethanol process proposed by (NREL Kazi et al., 2010), we follow a similar approach: we used the same feedstock, corn stover (see Table S1 in Supplementary Content); the same processing rate, 2,000 dry tons per day; and the same economic parameters and assumptions (see Table S2). We determine the minimum selling price (MSP) of biofuels which is the price that leads to zero net present value. For all strategies, we developed simulation models using ASPEN Plus Process Simulator (AspenPlusSimulatorV7.3, 2011). Based on the material and energy flows obtained from process simulations as well as the experimental data, unit equipment costs for all unit operation are estimated using Aspen Process Economic Analyzer (AspenProcessEconomicAnalyzerV7.3, 2011), except for the biomass handling, wastewater treatment and power generation sections, which are scaled based on a National Renewable Energy Laboratory (NREL) report (Kazi et al., 2010). All the equipment cost is indexed to year 2007, using the Chemical Engineering Plant Cost Index (Lozowski, 2012). The equipment and utility costs of the heat exchanger network (HEN) are calculated using Aspen Energy Analyzer (AspenEnergyAnalyzerV7.3, 2011). The investment for initial material loading at the startup, including catalyst and solvent loading, is considered as a part of the working capital. We assumed that $10 \%$ of the catalyst is refurbished every 6 months at a cost equivalent to $20 \%$ of its original value.

\subsection{Modeling of Units}

The modeling of the major unit operations (e.g., reactors, multi-stage extraction unit) is based on experimentally determined parameters (e.g., yields, reaction rates, partition coefficients), while modeling of process units for which experimental results are not available (e.g., distillation columns and flash vessels) is based on process simulations. Details can be found in the papers introducing the five strategies (Sen et al., 2012c; Sen et al., 2012a; Sen et al., 2012b; Han et al., 2014; Han et al., 2015). 
The sizing of the continuously stirred batch reactors is based on the reactor residence time and the feed flow. To calculate the size of the plug flow reactors, we used experimentally obtained reaction rates, catalyst properties (e.g., catalyst density and void fraction), and feed flows. Importantly, to accurately model the vapor-liquid equilibrium in $\mathrm{CO}_{2}$ separation system in strategy $\mathrm{E}$ we used experimental results to adjust parameters in the Peng-Robinson equation of state (EOS). Similarly, the selection of the most appropriate solvent as well as the estimation of partition coefficients for single stage extraction, which were used for the modeling of multi-stage extraction units, were based on experiments. The BA solvent used in strategy A was selected among other acetate solvents (e.g., ethyl, propyl, isobutyl and isoamyl acetates), because it is inexpensive and it has adequate selectivity for the desired extraction process (Sen et al., 2012d). However, the low boiling point of the BA solvent is a major drawback. As an alternative to BA solvent, the use of SBP solvent used in strategy C (interestingly, identified by undergraduate students in a summer lab course at the University of Wisconsin-Madison), resulted in significant operating and capital cost savings.

\subsection{Heat Integration and Power Generation}

For all strategies, we performed heat integration to minimize the utility requirements, while the remaining requirements are satisfied from the combustion of the biomass residues, as shown in Fig. 9. In a boiler, hot combustion gases are used to produce superheated steam for electricity generation in a turbine. The vapor fraction of the turbine outlet is condensed to reduce the work for pressurizing the fluid. Note that the turbine outlet pressure is optimized to maximize the heat recovery of the overall process. For example, the optimized pressure of the turbine outlet for strategy A is found to be 1 bar, whereas it is 1.7 bar for strategies $\mathrm{B}$ and $\mathrm{C}$, so that the heating requirement for evaporation of water (and FA) before extraction (see section 4.4) could be satisfied from the condensation of steam (turbine outlet) in the power cycle. The remaining energy of the combustion gases is used to preheat the air entering the fired heater. The efficiency of the transformation of biomass energy content (235 MW) to net power (power generated in the turbine minus power used in the power cycle) is found to be $25 \%$ for strategy $\mathrm{C}$ using loblolly pine feedstock (Fig. 9).

\subsection{Alternative Designs}

We explored different alternative designs that can substantially improve the economics of the proposed strategies. As an example, the base case design of strategy $\mathrm{C}$ had high solvent (SBP) and separation costs, because it initially resulted in a low concentration of intermediates (LA, FA, and GVL) after cellulose deconstruction, which in turn increased the capital and operating cost requirements for separation processes (initial design shown in Figure S1 in Supplementary Content). To overcome this challenge, we developed an alternative design by adding an evaporator before the extraction process to remove the water and FA in the cellulose deconstruction stream (Fig. S2 and Fig. 4), thereby significantly reducing water loading in downstream processing. Though more make-up hydrogen needs to be supplied (since decomposition of the remaining FA will not produce enough hydrogen for complete LA reduction), the final design has a lower MSP of butene oligomers (Sen et al., 2012a). The disadvantage of the final 
design is that fossil-fuel-derived hydrogen is needed, which means that the net renewable output is reduced. Specifically, the energy content of the natural gas needed to produce the required hydrogen corresponds to approximately $15 \%$ of the energy content of the produced biofuel.

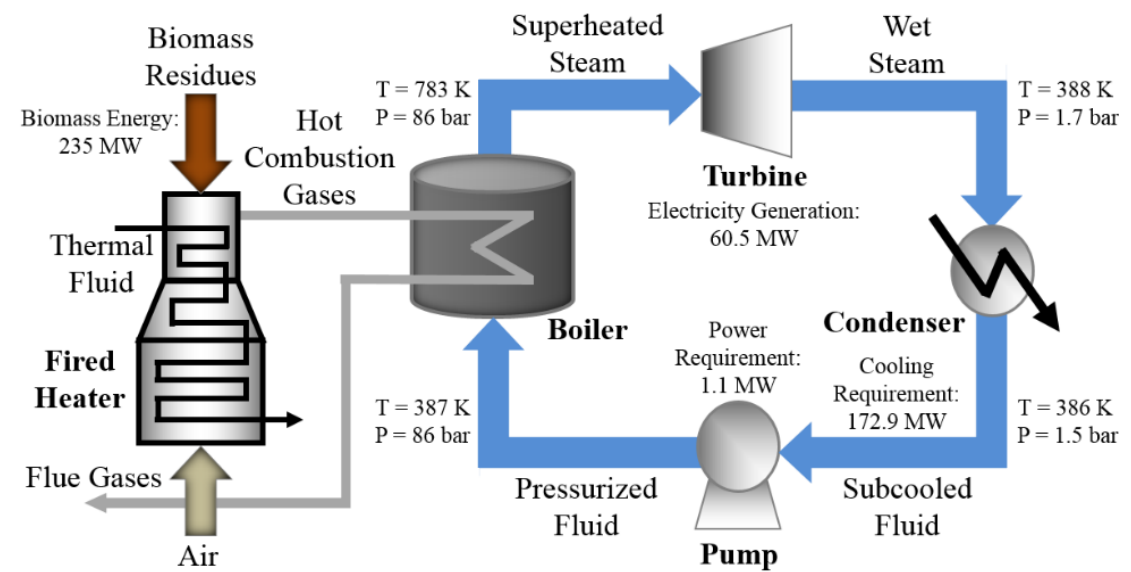

Fig. 9 Power cycle model for thermal fluid heating and electricity generation (strategy C) (Sen et al., 2012a). Hot gases obtained from combustion of biomass residues are used for heat and electricity generation.

Finally, we evaluated different feedstock alternatives because the selection of feedstock impacts the total operating costs. For this evaluation, the biomass-to-fuel yields as well as decisions such as the inclusion or not of a boiler/turbogenerator unit and the utilization of biomass residues (e.g., electricity generation vs. biomass residue sale) can play an important role. A summary of the results of these studies is presented in section 6.

\section{Energy Efficiency}

A comparison of the five strategies in terms of energy efficiency is shown in Table 1. After heat integration, the total energy (heating and electricity) requirements for all strategies could be satisfied from the combustion of biomass residues. The total heating requirements for strategies A-C are significantly lower than those of strategies D and E, mainly due to heating requirements for GVL recovery in strategies $\mathrm{D}$ and $\mathrm{E}$. The heating requirement of strategy $\mathrm{E}$ is quite high $(242.3 \mathrm{MW})$, because the sugar production system needs a higher amount of GVL loading. However, it is important to note that the heating requirement of strategy $\mathrm{E}$ becomes lower than that of strategy $\mathrm{D}$ after heat integration. The heating requirements of strategies $\mathrm{B}$ and $\mathrm{C}$ are higher compared to strategy A before heat integration, because strategies $\mathrm{B}$ and $\mathrm{C}$ require an evaporation step to remove most of the water that leads to a concentrated stream of intermediates for downstream conversions. The electricity requirement of strategy $\mathrm{E}$ is quite high (13.9 MW) due to compression of $\mathrm{CO}_{2}$ used for extraction. In addition, strategies A-C result in a significantly higher electricity production (64.6-72.8 MW) than those of strategies D and E (5.3-18 MW), but have much lower fuel production (64.5-68.3 MW) compared to strategies D and E (115 and 147.8 MW, respectively). This difference is mainly due to the fact that strategies A-C have lower heating requirements and also utilize the hemicellulose for power generation instead of being converted to liquid 
fuels. For all strategies, the energy efficiency, which is the ratio of the energy output (liquid fuels and excess electricity) to the energy input (biomass energy content), is estimated to be in the range of 33.2\%$42.4 \%$.

Table 1. Comparison of energy requirements and production of each strategy.

\begin{tabular}{lrrrrr}
\hline Strategy & A & B & C & D & E \\
\hline Energy requirements (MW) & & & & & \\
Heating requirements (before heat integration) & 51.9 & 68.0 & 73.8 & 195.4 & 242.3 \\
Heating requirements (after heat integration) & 5.3 & 0.6 & 41.5 & 93.7 & 74.4 \\
Electricity requirements & 0.1 & 0.2 & 0.2 & 1.4 & 13.9 \\
Energy production (MW) & & & & & \\
Fuel production & 67.6 & 64.5 & 68.3 & 115.0 & 147.8 \\
Excess electricity production & 71.0 & 72.6 & 64.4 & 3.9 & 4.1 \\
Net total energy production (MW) & 138.6 & 137.1 & 132.7 & 118.9 & 151.9 \\
Energy efficiency (\%) & 38.7 & 38.3 & 37.1 & 33.2 & 42.4 \\
\hline Energy contents of corn stover: cellulose = 139.1 MW, hemicellulose = 81.4 MW, lignin = 97.9 MW, \\
and others = 40.0 MW (total energy content of biomass: 358 MW) \\
*** Energy contents of biomass residues: strategies A-C = 261.4 MW, strategy D = 200.1 MW, and \\
strategy E = 164.9 MW
\end{tabular}

\section{Economic Evaluation}

A comparison of capital and operating costs for all strategies is shown in Table 2. The total annualized capital costs for strategies A-C are found to be 80.0-82.0 million $\mathrm{yr}^{-1}$. In these strategies, the costs of the heat/power generation unit and the biomass pretreatment (for hemicellulose removal) are the major components of the total capital cost (61.9\%-63.5\% of the total capital costs). The total annualized capital cost for strategy $\mathrm{D}$ is estimated to be 65.2 million $\mathrm{yr}^{-1}$, which is $23.0 \%-26.2 \%$ lower than that of strategies A-C mainly because it has no hemicellulose removal step ( $\$ 14.0$ million $\mathrm{yr}^{-1}$ of difference) and a smaller heat/power generation unit ( $\$ 15.6$ million $\mathrm{yr}^{-1}$ of difference). The total annualized capital cost for strategy $\mathrm{E}\left(85.2\right.$ million $\mathrm{yr}^{-1}$ ) is $30.7 \%$ higher than that of strategy $\mathrm{D}$ because it requires a larger reactor system for production of sugars ( $\$ 18.3$ million $\mathrm{yr}^{-1}$ of difference) due to a lower solid loading (7 wt $\%$ ) compared to strategy $\mathrm{D}(16 \mathrm{wt} \%)$. In addition, strategy E requires more expensive separation steps for recovery of sugars ( $\$ 16.2$ million $\mathrm{yr}^{-1}$ of difference). The total operating costs of strategies $\mathrm{D}$ and $\mathrm{E}$ (\$77.8 and 83.8 million $\mathrm{yr}^{-1}$, respectively) are lower than those of strategies A-C (\$87.1-94.4 million $\mathrm{yr}^{-1}$ ) mainly due to lower material costs. Feedstock cost is the most significant portion of total operating cost for all strategies (61.3\%-74.4\% of the total operating costs). Compared to strategy E, the total operating costs of strategy D is $7.9 \%$ lower ( $\$ 6.0$ million $\mathrm{yr}^{-1}$ ) due to lower material costs (sulfuric acid and $\mathrm{CO}_{2}$ costs, $\$ 2.8$ million $\mathrm{yr}^{-}$ ${ }^{1}$ ) and fixed operating costs $\left(\$ 4.8\right.$ million $\left.\mathrm{yr}^{-1}\right)$, which are proportional to the capital cost. As a result, the total production cost, which is equal to the sum of annualized capital and operating costs, is lower for strategy D (\$143.0 million $\mathrm{yr}^{-1}$ ) compared to other strategies.

Figure 10 shows that the MSPs for strategies A-C are significantly higher (more than 1.7 times) than strategies D and E due to their significantly lower (more than 1.7 times) fuel production, despite similar 


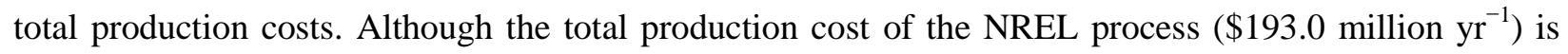
$35.0 \%$ higher than that of strategy D ( $\$ 143.0$ million $\mathrm{yr}^{-1}$ ), the MSP for the NREL process $(\$ 5.13$ per gallon of gasoline equivalent (GGE)) is $30 \notin$ per GGE lower than that for strategy D $\left(\$ 5.43 \mathrm{GGE}^{-1}\right)$,

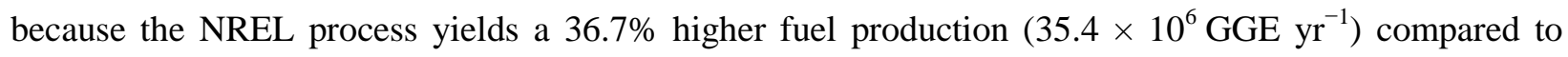

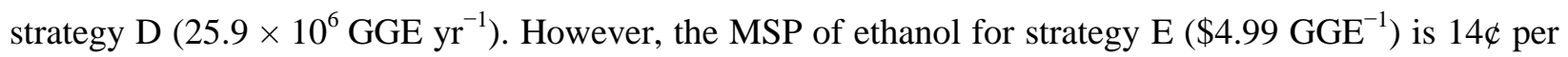
GGE lower than that of the NREL process despite its lower ethanol production $\left(5.6 \% ; 1.9 \times 10^{6} \mathrm{GGE}\right.$ $\mathrm{yr}^{-1}$ ) due to its lower total production cost (14.4\%; $\$ 23.9$ million $\left.\mathrm{yr}^{-1}\right)$, which results because strategy $\mathrm{E}$ uses a less expensive catalytic conversion instead of using expensive enzymes for sugar production (\$37.1 million $\mathrm{yr}^{-1} ; \$ 1.05 \mathrm{GGE}^{-1}$ ). The capital and operating cost contributions of each processing section to the MSP of liquid fuels are shown in Fig. 11. The major cost contributor to the MSP is the feedstock cost (\$1.73-3.97 $\left.\mathrm{GGE}^{-1} ; 34.7-41.1 \%\right)$ for all strategies. Also, the heat/power generation unit has a significant contribution to the MSP in all cases. Cost contributions of the heat/power generation unit for strategies A$\mathrm{C}\left(\$ 2.87-3.00 \mathrm{GGE}^{-1} ; 30.6-31.2 \%\right)$ are significantly higher compared to strategies D and E (\$0.70-1.03 $\left.\mathrm{GGE}^{-1} ; 14.0-19.0 \%\right)$, because strategies A-C also utilize the hemicellulose fraction for steam generation.

As an alternative to corn stover, loblolly pine is found to be a more appropriate feedstock for strategies A$\mathrm{C}$ due to its high cellulose content (55 wt\%) and lower price (\$57 per dry ton) (Han et al., 2014). We assume that the hemicellulose removal step is unnecessary for processing loblolly pine due to its low xylan content (ca. $7 \mathrm{wt} \%$ ) (Sen et al., 2012a). This assumption considerably reduces the capital investment and the amount of $\mathrm{C}_{6}$-sugars that would have been removed with the hemicellulose fraction, such as mannose and galactose. The use of loblolly pine reduced the MSPs obtained from strategies A-C (by $36-39 \%$ ) to $\$ 6.01 \mathrm{GGE}^{-1}, \$ 6.35 \mathrm{GGE}^{-1}$, and $\$ 5.69 \mathrm{GGE}^{-1}$, respectively, due to $51-53 \%$ decreases in feedstock cost.

Table 2. Comparison of annualized capital and operating costs for all strategies ( $\$$ million $\mathrm{yr}^{-1}$ ). Based on $10 \%$ discount rate and an equipment lifespan of 20 years, a capital recovery factor of $11.75 \%$ is used to annualize the capital costs.

\begin{tabular}{|c|c|c|c|c|c|c|c|c|c|c|}
\hline \multirow[b]{2}{*}{ Components } & \multicolumn{2}{|c|}{ Strategy A } & \multicolumn{2}{|c|}{ Strategy B } & \multicolumn{2}{|c|}{ Strategy C } & \multicolumn{2}{|c|}{ Strategy D } & \multicolumn{2}{|c|}{ Strategy E } \\
\hline & $\mathbf{C}$ & $\mathbf{O}$ & C & $\mathbf{O}$ & $\mathrm{C}$ & $\mathbf{O}$ & $\mathbf{C}$ & $\mathbf{O}$ & $\mathbf{C}$ & 0 \\
\hline \multicolumn{11}{|l|}{ Process sections } \\
\hline Pretreatment & 14.0 & 12.0 & 14.0 & 12.0 & 14.0 & 12.0 & & & & \\
\hline Biomass deconstruction & 7.8 & 1.4 & 7.6 & 1.2 & 7.8 & 1.2 & 14.0 & 2.6 & 32.3 & 6.1 \\
\hline GVL production & 3.1 & 4.2 & 3.1 & 3.7 & 1.9 & 0.9 & 4.2 & 4.1 & & \\
\hline SA recovery & 2.3 & 1.7 & 4.5 & 0.6 & 5.1 & 3.2 & & & & \\
\hline GVL recovery & 3.6 & 0.5 & 0.9 & 0.1 & 1.1 & 0.2 & 6.5 & 1.0 & & \\
\hline $\mathrm{CO}_{2}$ extraction & & & & & & & & & 12.6 & 3.4 \\
\hline Ethanol production & & & & & & & & & 2.7 & 6.6 \\
\hline Ethanol purification & & & & & & & & & 5.1 & 0.7 \\
\hline $\mathrm{CO}_{2}$ separation & & & & & & & & & 3.6 & 0.6 \\
\hline GVL production & & & & & & & & & 0.8 & 0.2 \\
\hline Biomass residues separation & & & & & & & & & 0.9 & 0.1 \\
\hline Butene oligomers production & 5.3 & 0.7 & 6.9 & 1.0 & 5.2 & 0.7 & 7.2 & 1.1 & & \\
\hline Heat and power production & 36.8 & 7.1 & 36.7 & 7.1 & 36.8 & 7.1 & 21.2 & 5.4 & 18.3 & 5.2 \\
\hline
\end{tabular}


Other processing sections

Feedstock cost

$9.0 \quad 8.8$

57.9

$8.1 \quad 3.4$

8.1

8.4

12.1

5.6

$\begin{array}{ll}8.9 & 2.9\end{array}$

Total capital/operating cost

$82.0 \quad 94.4$

57.9

57.9

Total cost

176.4

$65.2 \quad 77.7$

$85.2 \quad 83.8$

C: annualized capital cost; O: operating cost.

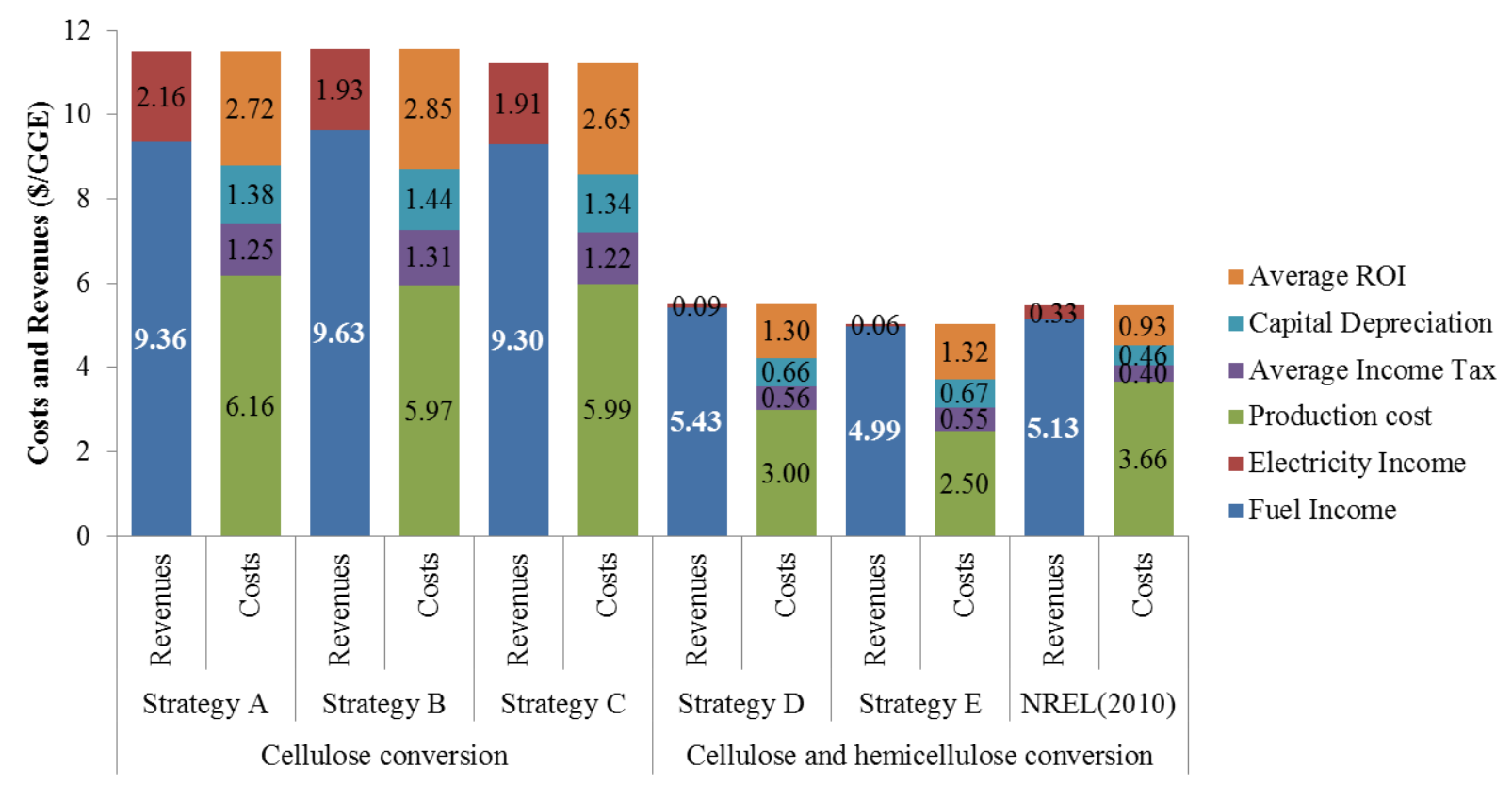

Fig. 10 Comparison of costs and revenues of the catalytic conversion strategies with the NREL's lignocellulosic ethanol production strategy using corn stover feedstock (Kazi et al., 2010). 


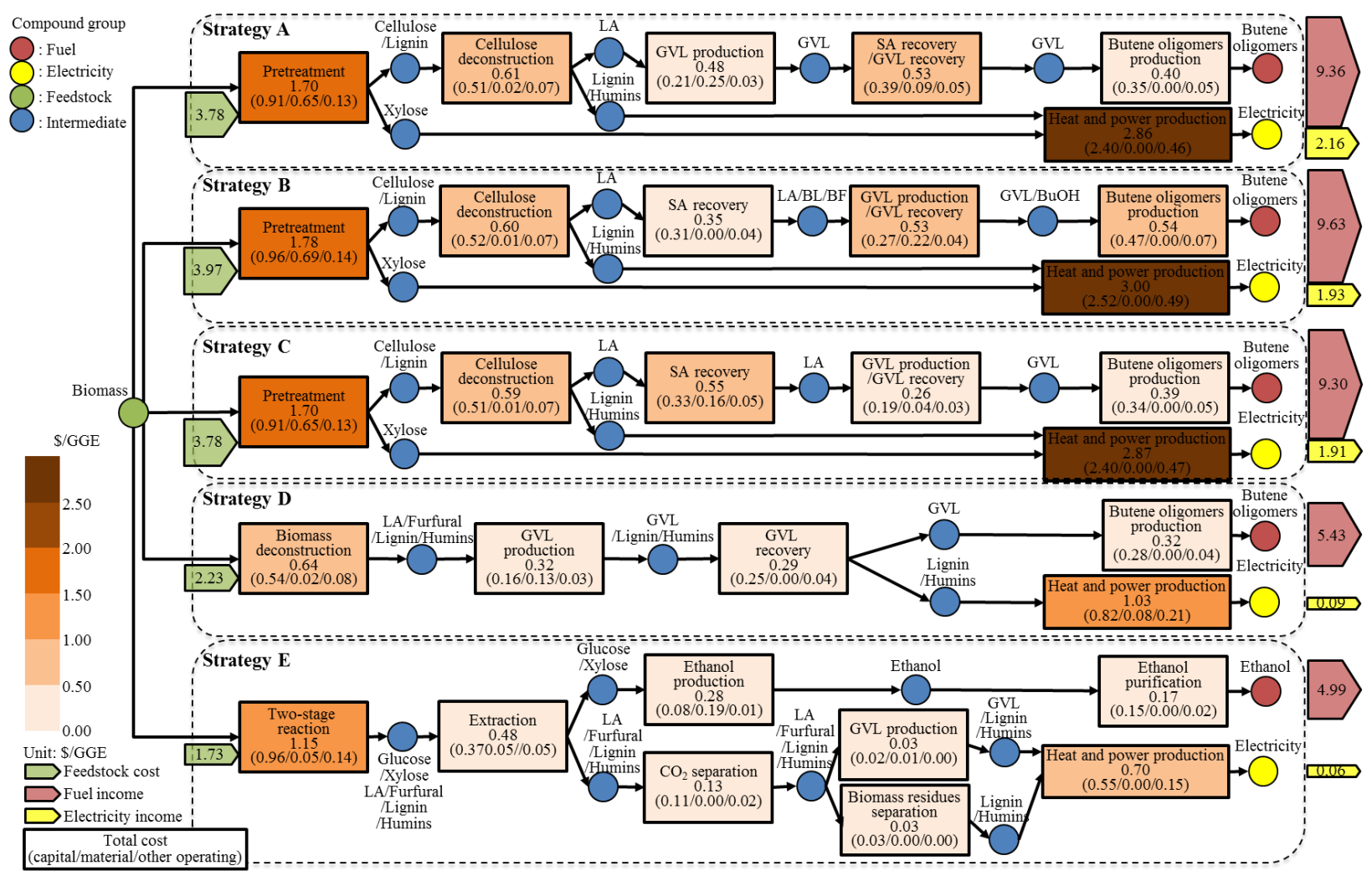

Fig. 11 Capital and operating cost contributions of each processing section to the MSP for the catalytic conversion strategies (using corn stover).

In addition, hybrid poplar is found to be the best option for strategy D due to its high sugar content ( 65 $\mathrm{wt} \%$ ) and lower price (\$51 per dry ton), which in turn, requires less amount of feedstock for producing the same amount of fuel (Han et al., 2014). Moreover, we developed an alternative design for strategy D, in which there is no electricity generation and electricity is externally supplied. In this design, biomass residues are only used for producing heat required for the process, while the excess residues are disposed or sold as fuel. If biomass residues are disposed or sold, then the MSP, using hybrid poplar feedstock, can be further decreased to $\$ 4.29 \mathrm{GGE}^{-1}$ or $\$ 4.01 \mathrm{GGE}^{-1}$, respectively (Han et al., 2014).

\section{Discussion}

We performed sensitivity analyses on various key parameters to identify areas of possible cost improvements (Fig 12). First, we observed that the feedstock price shows a similar impact on the MSP for strategies A-D (Fig 12a); e.g., MSP decreases by $11 \%$ as the feedstock price is reduced from $\$ 83 /$ ton (base case) to $\$ 60 /$ ton (Humbird et al., 2011). A similar variation in feedstock price leads to a lower decrease $(9.6 \%)$ in the MSP for strategy E, because this strategy has the highest biomass-to-fuel yield. Also, we studied the impact of biomass residue utilization (electricity generation vs. sale). In the base case, biomass residues are burned to produce heat and electricity required for the process, and the excess electricity is sold to the grid to generate additional revenue. As an alternative to excess electricity generation, lignin can be potentially used to produce chemicals and fuels (Holladay et al., 2007; Azadi et 
al., 2012; Joffres et al., 2013). However, the use of lignin as an intermediate for chemical and fuel production requires additional processing steps that can be costly. Instead, we investigated a scenario in which only a portion of biomass residues is used for steam production to satisfy heating requirements, while the excess biomass residues are sold as a low-quality fuel at $\$ 55 /$ ton (Holladay et al., 2007). A $100 \%$ increase in electricity price (base case scenario: $5.4 \phi \mathrm{kW} . \mathrm{h}^{-1}$ U.S.EIA, 2012) decreases the MSP for strategies A-C by $\sim 20 \%$, but it does not lead to substantial improvements for strategies D and E (1\%) as expected. An increase in selling price of the residues from $\$ 55 /$ ton to $\$ 88 /$ ton leads to a higher improvement (7-10\%) in the MSP for strategies A-C than strategies D and E (2\%), because strategies A-C have more excess biomass residues available.

In strategies A-C, the hemicellulose, mainly containing xylose, is solubilized and recovered by dilute acid pretreatment, and used to produce heat and generate electricity. As an alternative to burning, xylose can be used as an intermediate for producing valuable chemicals. Therefore, we investigated a scenario, in which we sell xylose to generate extra revenue instead of burning it. In this scenario, we observed that the MSP decreases by $\sim 20 \%$ for strategies A-C, when the xylose stream is valued at $20 \notin$ per $\mathrm{kg}$ (Fig 12b). This analysis indicates that to produce liquid fuels competitively, all fractions of lignocellulosic biomass must be converted into value-added products. Therefore, further research is required towards the effective conversion and/or upgrading of all three fractions, cellulose, hemicellulose and lignin.

In addition to economic parameters, we also studied how technical parameters affect the MSP. In Fig 12c, the impact of variations in catalyst lifetime is shown. A decrease in catalyst lifetime from 6 months (base case) to one month, which increase catalyst regeneration cost, leads to greater increases in the MSP of strategies A, B and D (10-17\%) than strategies C and E (0-2\%), due to the cost of precious metals used in the catalysts in strategies $\mathrm{A}$ ( $\mathrm{RuRe} / \mathrm{C}$ for $\mathrm{GVL}$ production) and $\mathrm{B}(\mathrm{Pd} / \mathrm{C}$ for $\mathrm{FA} / \mathrm{BF}$ conversion to hydrogen) and high catalyst loading (strategy D). 

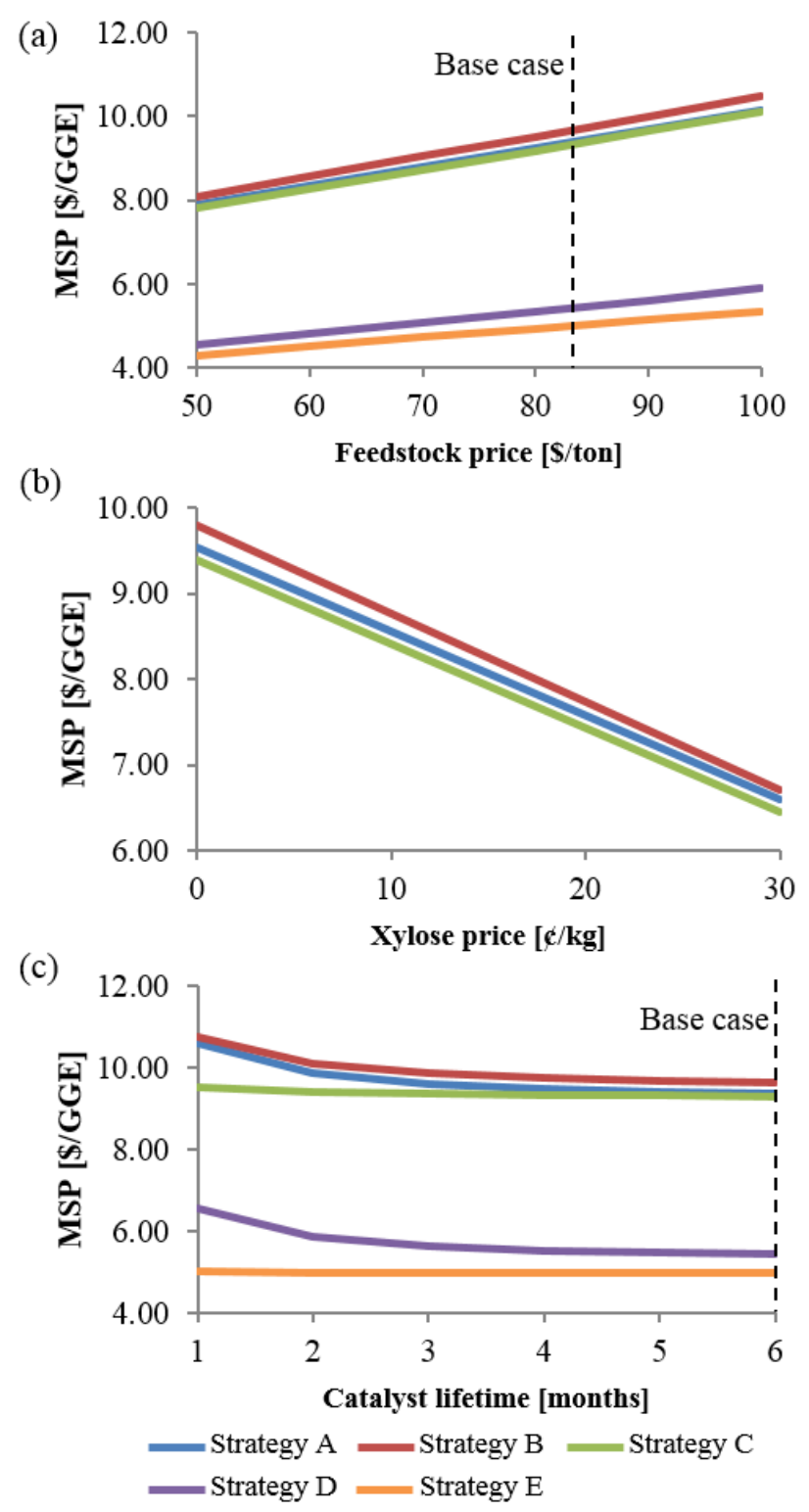

Fig. 12 Sensitivity of the MSP with respect to (a) feedstock price, (b) xylose selling price, and (c) catalyst lifetime. Base case shown by dashed lines.

In addition, we analyzed the case in which excess biomass residues are disposed instead of being used for electricity generation (Fig. 13). Disposing of residues is always a suboptimal strategy compared to biomass residue sale, and also less energy efficient compared to the base case (with electricity generation), because residues could be utilized as a fuel. However, disposing residues results in a better MSP compared to the base case due to the high capital cost of the turbogenerator unit. Furthermore, we investigated the trade-off between selling excess biomass residues and bioelectricity (generated from residues) based on the variations in selling prices of both by-products using strategy $\mathrm{C}$ as a case study (Fig. 14). In region C, producing and selling bioelectricity is a better option than selling biomass residues, while selling biomass residues is a better option in region $\mathrm{C}^{*}$. For example, if the price of biomass residues is $\$ 20 /$ ton, then electricity generation becomes a better option if the price of bioelectricity is 
higher than $6.25 \notin \mathrm{kW} \cdot \mathrm{h}^{-1}$ (region C). As a result, selling residues is always a more cost-effective option than electricity generation for the base case scenario (electricity price: $5.4 \notin \mathrm{kW} \cdot \mathrm{h}^{-1}$ ).

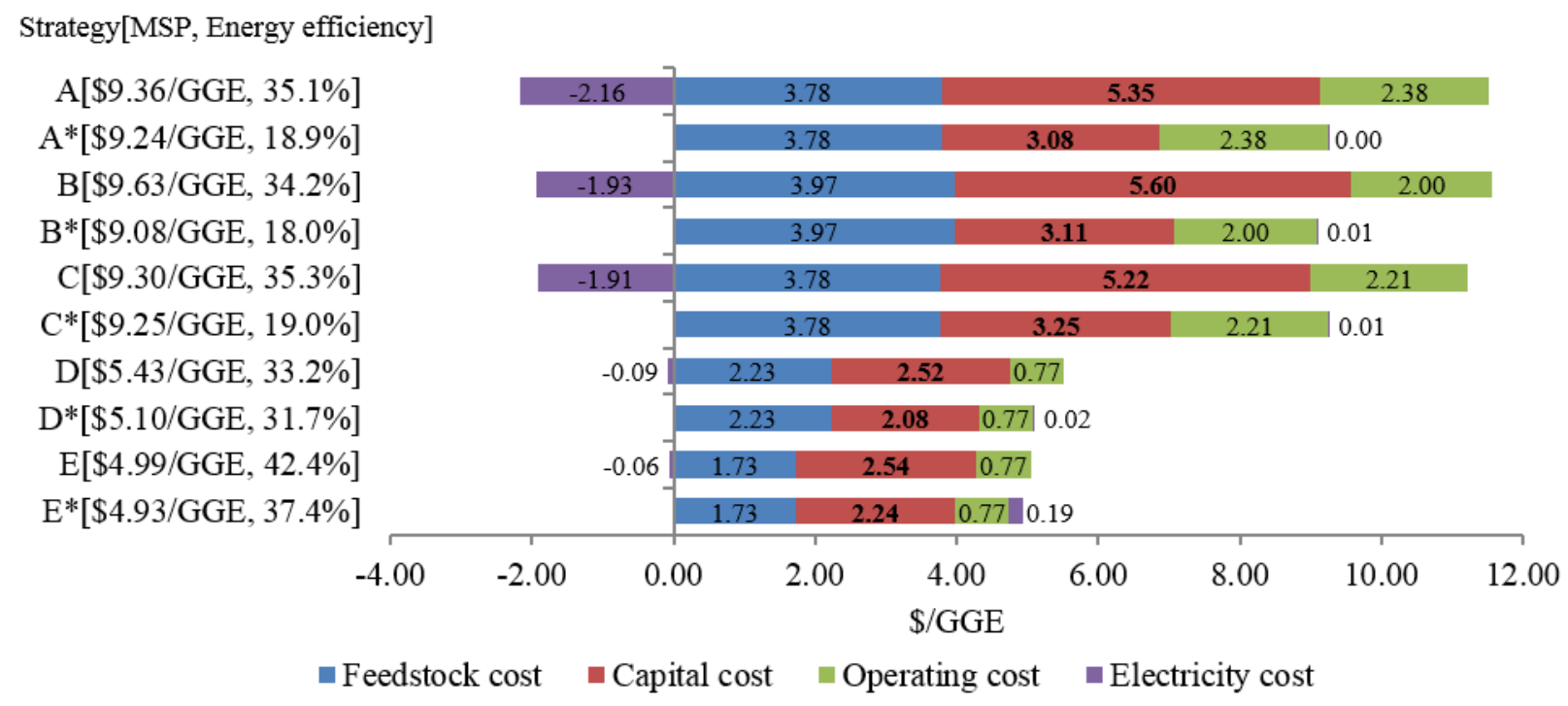

Fig. 13 Comparison of base case (electricity generation) with alternative cases (biomass residue disposal) (* indicates biomass residues disposal: $\mathrm{A}^{*}, \mathrm{~B}^{*}, \mathrm{C}^{*}, \mathrm{D}^{*}$, and $\mathrm{E}^{*}$ )

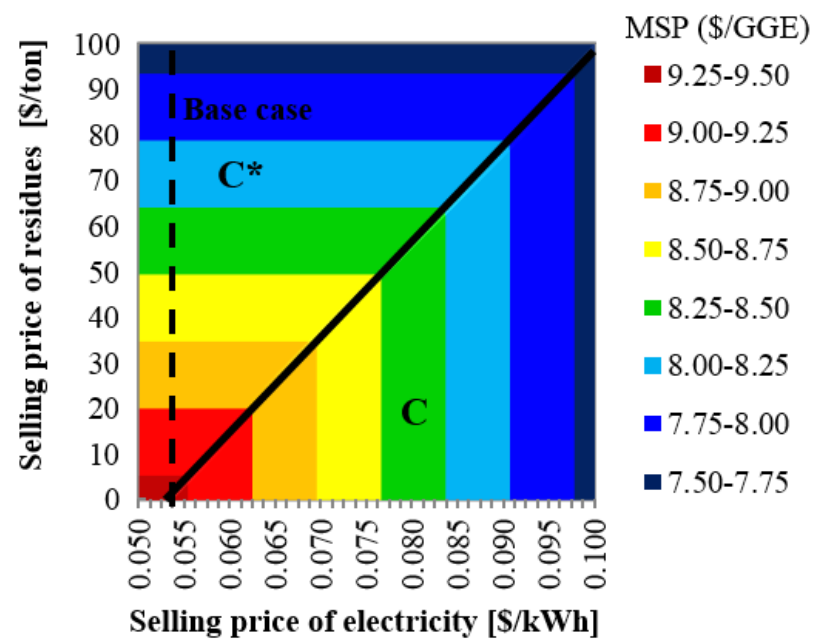

Fig. 14 Trade-off between selling biomass residues and bioelectricity. Producing and selling bioelectricity is a better option than selling biomass residues in region $\mathrm{C}$, while selling residues is better in region $\mathrm{C}^{*}$. As an example, a bioelectricity selling price higher than $6.25 \phi \mathrm{kW} \cdot \mathrm{h}^{-1}$ at a price of $\$ 20 /$ ton for biomass residues makes electricity generation more cost-effective option.

We also studied the impact of variations in feedstock costs and compositions (Fig. 15). At a price of $\$ 80 /$ ton, an increase in the $\mathrm{C}_{5} / \mathrm{C}_{6}$ content of biomass from $65 \mathrm{wt} \%$ (base case) to $70 \mathrm{wt} \%$ (e.g., sugar cane de Souza et al., 2013) leads to a 7.2\% decrease in the MSP for strategy E, as a result of an increase in ethanol production. If the $\mathrm{C}_{5} / \mathrm{C}_{6}$ content is $70 \%$ and the feedstock price is reduced to $\$ 60 /$ ton, then the MSP decreases to $\$ 4.21 \mathrm{GGE}^{-1}$ (by $15 \%$ ), which means that the development of biomass crops with high sugar content and low cost has the potential to significantly reduce the biofuel production costs. 
Lastly, we studied the trade-off between feedstock cost and total capital investment, both of which depend on the capacity of the plant. Specifically, an increase in plant capacity leads to higher feedstock costs, since the average crop transport distance increases, but it leads to lower total unit capital cost due to economies of scale. A detailed description of our methodology can be found in a previous study (Sen et al., 2012d). For strategy A using loblolly pine, the minimum MSP is obtained at plant capacity equal to 8,000 metric tons (MT) per day (Fig. 16). However, smaller plants are preferable since the total capital investment can be the major barrier for the implementation of this type of technology. Therefore, choosing a biomass processing capacity between 1,000 and 2,500 MT/day (that requires a total capital investment of \$300-600 million) appears to be more attractive. For this capacity range, the MSP of butene oligomers is in the range of \$5.50-6.30 per GGE. In the base case, processing rate of 1,365 MT per day of loblolly pine results in the MSP of $\$ 6.01$ per GGE for strategy A.

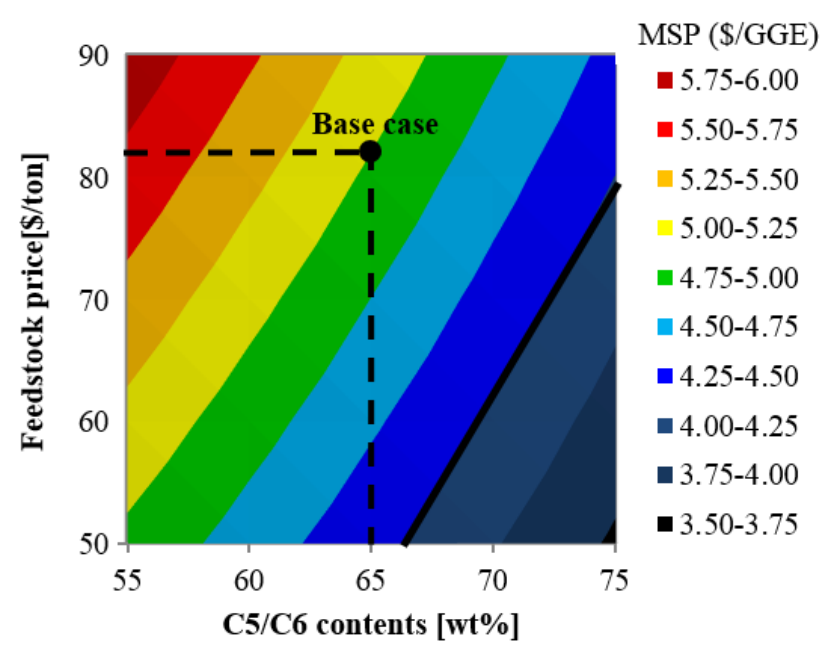

Fig. 15 Sensitivity of the MSP with respect to the feedstock price and the $\mathrm{C}_{5} / \mathrm{C}_{6}$ contents for strategy $\mathrm{E}$. The black dot and straight line on the figure represent the corresponding base case values for corn stover, and the current ethanol market price in terms of \$ per GGE, respectively.

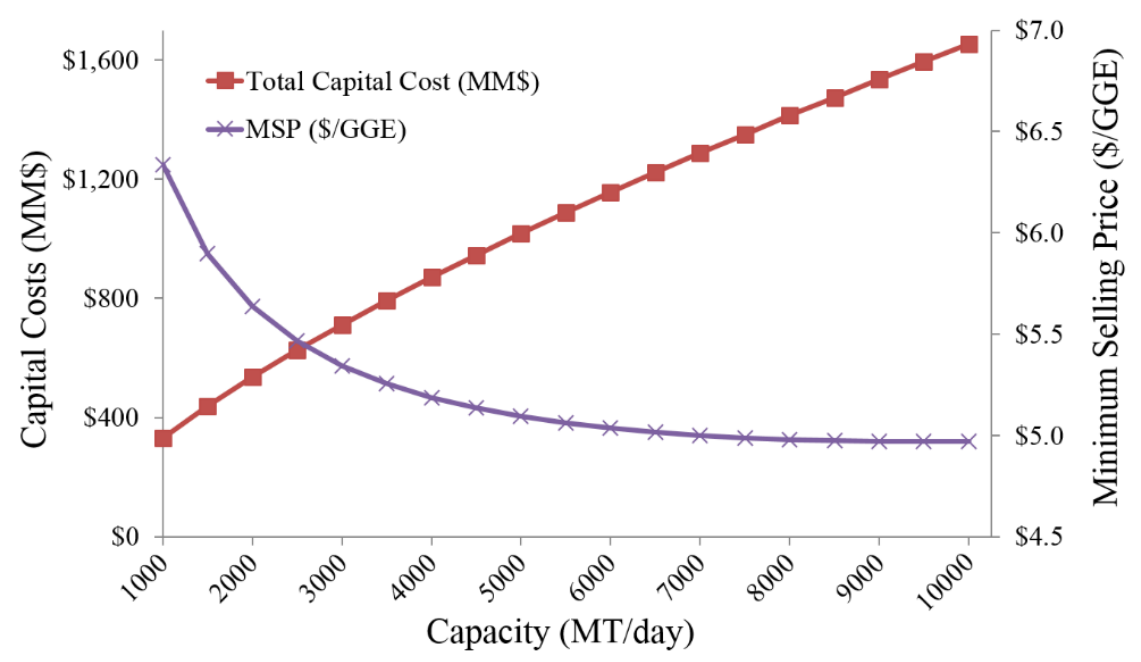

Fig. 16 Variations of the total capital investment and the MSP based on the plant capacity for strategy A using loblolly pine (base case MSP for processing 1,365 MT per day of loblolly pine: \$6.01/GGE). Capital cost scaling exponent of 0.7 is used for capital cost estimation. 


\section{Conclusions}

The main goal of this paper was to show how process systems engineering and experimental heterogeneous catalysis studies can be coupled to identify promising research directions. We synthesized five catalytic biofuel strategies through production of platform chemicals, such as LA and sugars, and we compared these catalytic strategies with the lignocellulosic ethanol process reported by the NREL. We showed that strategies that rely only on the conversion of cellulose (A-C) are limited due to the low biomass-to-fuels yield. To overcome this challenge, we synthesized strategies that simultaneously convert the cellulose and hemicellulose fractions (D and E), leading to higher yields and lower unit capital investment, which in turn lead to better economics. This further suggests that developing technologies for efficient lignin conversion could make biofuels processes even more attractive. A comparison of strategy $\mathrm{D}$ and $\mathrm{E}$ showed that the latter results in a better MSP $\left(\$ 4.99 \mathrm{GGE}^{-1}\right)$ due to its significantly higher fuel production despite its slightly higher production cost. Additionally, strategy E offers a more flexible platform, in which sugars can be chemically or biologically upgraded into various types of chemicals and fuels. Thus, our preliminary analysis suggests that strategy E could become economically competitive alternative to current biofuel production approaches. More generally, we hope we were able to illustrate how systems engineering methods can be used synergistically with research efforts in basic science to identify technological bottlenecks and cost drivers, thereby guiding research efforts.

\section{Acknowledgements}

This work was funded by the DOE Great Lakes Bioenergy Research Center (DOE BER Office of Science DE-FC02-07ER64494).

$\begin{array}{ll}\text { Abbreviations } \\ \text { PSE } & \text { process systems engineering } \\ \text { LA } & \text { levulinic acid } \\ \text { FA } & \text { formic acid } \\ \text { SA } & \text { sulfuric acid } \\ \text { GVL } & \gamma \text {-valerolactone } \\ \text { BL } & \text { sec-butyl levulinate } \\ \text { BF } & \text { sec-butyl formate } \\ \text { BA } & \text { butyl acetate } \\ \text { GGE } & \text { gallon of gasoline equivalent } \\ \text { SBP } & \text { 2-sec-butyl phenol } \\ \text { NREL } & \text { National Renewable Energy Laboratory } \\ \text { HEN } & \text { heat exchanger network } \\ \text { MSP } & \text { minimum selling price } \\ \text { EOS } & \text { equation of state } \\ \text { MT } & \text { metric tons }\end{array}$




\section{References}

Aden, A. and T. Foust (2009). Technoeconomic analysis of the dilute sulfuric acid and enzymatic hydrolysis process for the conversion of corn stover to ethanol. Cellulose 16(4): 535-545.

Alonso, D. M., J. Q. Bond and J. A. Dumesic (2010). Catalytic conversion of biomass to biofuels. Green Chemistry 12(9): 1493-1513.

Alonso, D. M., S. G. Wettstein, J. Q. Bond, T. W. Root and J. A. Dumesic (2011). Production of Biofuels from Cellulose and Corn Stover Using Alkylphenol Solvents. ChemSusChem 4(8): 1078-1081.

Alonso, D. M., S. G. Wettstein and J. A. Dumesic (2012). Bimetallic catalysts for upgrading of biomass to fuels and chemicals. Chemical Society Reviews 41(24): 8075-8098.

Alonso, D. M., S. G. Wettstein, M. A. Mellmer, E. I. Gurbuz and J. A. Dumesic (2013). Integrated conversion of hemicellulose and cellulose from lignocellulosic biomass. Energy \& Environmental Science 6(1): 76-80.

Anex, R. P., A. Aden, F. K. Kazi, J. Fortman, R. M. Swanson, M. M. Wright, J. A. Satrio, R. C. Brown, D. E. Daugaard, A. Platon, G. Kothandaraman, D. D. Hsu and A. Dutta (2010). Techno-economic comparison of biomass-to-transportation fuels via pyrolysis, gasification, and biochemical pathways. Fuel 89, Supplement 1(0): S29-S35.

AspenEnergyAnalyzerV7.3 (2011). Aspen Technology Inc., Cambridge.

AspenPlusSimulatorV7.3 (2011). Aspen Technology Inc., Cambridge.

AspenProcessEconomicAnalyzerV7.3 (2011). Aspen Technology Inc., Cambridge.

Azadi, P., R. Carrasquillo-Flores, Y. J. Pagan-Torres, E. I. Guerbuez, R. Farnood and J. A. Dumesic (2012). Catalytic conversion of biomass using solvents derived from lignin. Green Chemistry 14(6): 15731576.

Baliban, R. C., J. A. Elia, C. A. Floudas, B. Gurau, M. B. Weingarten and S. D. Klotz (2013). Hardwood Biomass to Gasoline, Diesel, and Jet Fuel: 1. Process Synthesis and Global Optimization of a Thermochemical Refinery. Energy \& Fuels 27(8): 4302-4324.

Bals, B., C. Wedding, V. Balan, E. Sendich and B. Dale (2011). Evaluating the impact of ammonia fiber expansion (AFEX) pretreatment conditions on the cost of ethanol production. Bioresource Technology 102(2): 1277-1283.

Banerjee, G., S. Car, J. S. Scott-Craig, D. B. Hodge and J. D. Walton (2011). Alkaline peroxide pretreatment of corn stover: effects of biomass, peroxide, and enzyme loading and composition on yields of glucose and xylose. Biotechnology for Biofuels 4.

Bond, J. Q., D. M. Alonso, D. Wang, R. M. West and J. A. Dumesic (2010). Integrated Catalytic Conversion of $\gamma$-Valerolactone to Liquid Alkenes for Transportation Fuels. Science 327(5969): 1110-1114.

Bond, J. Q., A. A. Upadhye, H. Olcay, G. A. Tompsett, J. Jae, R. Xing, D. M. Alonso, D. Wang, T. Zhang, R. Kumar, A. Foster, S. M. Sen, C. T. Maravelias, R. Malina, S. R. H. Barrett, R. Lobo, C. E. Wyman, J. A. Dumesic and G. W. Huber (2014). Production of renewable jet fuel range alkanes and commodity chemicals from integrated catalytic processing of biomass. Energy \& Environmental Science 7(4): 1500-1523.

Bozell, J. J. and G. R. Petersen (2010). Technology development for the production of biobased products from biorefinery carbohydrates-the US Department of Energy's "Top 10" revisited. Green Chemistry 12(4): 539-554.

Braden, D. J., C. A. Henao, J. Heltzel, C. C. Maravelias and J. A. Dumesic (2011). Production of liquid hydrocarbon fuels by catalytic conversion of biomass-derived levulinic acid. Green Chemistry 13(7): 1755-1765.

Cardona, C. A. and Ó. J. Sánchez (2007). Fuel ethanol production: Process design trends and integration opportunities. Bioresource Technology 98(12): 2415-2457. 
Chheda, J. N., G. W. Huber and J. A. Dumesic (2007). Liquid-Phase Catalytic Processing of BiomassDerived Oxygenated Hydrocarbons to Fuels and Chemicals. Angewandte Chemie International Edition 46(38): 7164-7183.

Conde-Mejía, C., A. Jiménez-Gutiérrez and M. M. El-Halwagi (2013). Assessment of Combinations between Pretreatment and Conversion Configurations for Bioethanol Production. ACS Sustainable Chemistry \& Engineering 1(8): 956-965.

Dale, B. (2008). Biofuels: Thinking Clearly about the Issues. Journal of Agricultural and Food Chemistry 56(11): 3885-3891.

Daoutidis, P., W. A. Marvin, S. Rangarajan and A. I. Torres (2013). Engineering Biomass Conversion Processes: A Systems Perspective. AIChE Journal 59(1): 3-18.

de Souza, A. P., D. C. C. Leite, S. Pattathil, M. G. Hahn and M. S. Buckeridge (2013). Composition and Structure of Sugarcane Cell Wall Polysaccharides: Implications for Second-Generation Bioethanol Production. Bioenergy Research 6(2): 564-579.

Demirbas, A. (2007). Progress and recent trends in biofuels. Progress in Energy and Combustion Science 33(1): 1-18.

Eggeman, T. and R. T. Elander (2005). Process and economic analysis of pretreatment technologies. Bioresource Technology 96(18): 2019-2025.

Farrell, A. E., R. J. Plevin, B. T. Turner, A. D. Jones, M. O'Hare and D. M. Kammen (2006). Ethanol can contribute to energy and environmental goals. Science 311(5760): 506-508.

Floudas, C. A., J. A. Elia and R. C. Baliban (2012). Hybrid and single feedstock energy processes for liquid transportation fuels: A critical review. Computers \& Chemical Engineering 41(0): 24-51.

Gebreslassie, B. H., R. Waymire and F. You (2013). Sustainable design and synthesis of algae-based biorefinery for simultaneous hydrocarbon biofuel production and carbon sequestration. AIChE Journal 59(5): 1599-1621.

Gnansounou, E. and A. Dauriat (2010). Techno-economic analysis of lignocellulosic ethanol: A review. Bioresource Technology 101(13): 4980-4991.

Gong, J. and F. Q. You (2014). Optimal Design and Synthesis of Algal Biorefinery Processes for Biological Carbon Sequestration and Utilization with Zero Direct Greenhouse Gas Emissions: MINLP Model and Global Optimization Algorithm. Industrial \& Engineering Chemistry Research 53(4): 15631579.

Grossmann, I. E. and G. Guillén-Gosálbez (2010). Scope for the application of mathematical programming techniques in the synthesis and planning of sustainable processes. Computers \& Chemical Engineering 34(9): 1365-1376.

Gürbüz, E. I., D. M. Alonso, J. Q. Bond and J. A. Dumesic (2011). Reactive Extraction of Levulinate Esters and Conversion to $\gamma$-Valerolactone for Production of Liquid Fuels. ChemSusChem 4(3): 357-361.

Han, J., J. S. Luterbacher, D. M. Alonso, J. A. Dumesic and C. T. Maravelias (2015). A lignocellulosic ethanol strategy via nonenzymatic sugar production: Process synthesis and analysis. Bioresource Technology 182(0): 258-266.

Han, J., S. M. Sen, D. M. Alonso, J. A. Dumesic and C. T. Maravelias (2014). A strategy for the simultaneous catalytic conversion of hemicellulose and cellulose from lignocellulosic biomass to liquid transportation fuels. Green Chemistry 16(2): 653-661.

Hill, J., E. Nelson, D. Tilman, S. Polasky and D. Tiffany (2006). Environmental, economic, and energetic costs and benefits of biodiesel and ethanol biofuels. Proceedings of the National Academy of Sciences of the United States of America 103(30): 11206-11210.

Holladay, J. E., J. F. White, J. J. Bozell and D. Johnson (2007). Top Value-Added Chemicals from Biomass Volume II-Results of Screening for Potential Candidates from Biorefinery Lignin: Medium: ED; Size: PDFN. 
Huber, G. W., S. Iborra and A. Corma (2006). Synthesis of Transportation Fuels from Biomass: Chemistry, Catalysts, and Engineering. Chemical Reviews 106(9): 4044-4098.

Humbird, D., R. Davis, L. Tao, C. Kinchin, D. Hsu, A. Aden, P. Schoen, J. Lukas, B. Olthof and M. Worley (2011). Process Design and Economics for Biochemical Conversion of Lignocellulosic Biomass to Ethanol: Dilute-Acid Pretreatment and Enzymatic Hydrolysis of Corn Stover, National Renewable Energy Laboratory (NREL), Golden, CO.

Joffres, B., D. Laurenti, N. Charon, A. Daudin, A. Quignard and C. Geantet (2013). Thermochemical Conversion of Lignin for Fuels and Chemicals: A Review. Oil \& Gas Science and Technology-Revue D Ifp Energies Nouvelles 68(4): 753-763.

Kazi, F. K., J. A. Fortman, R. P. Anex, D. D. Hsu, A. Aden, A. Dutta and G. Kothandaraman (2010). Technoeconomic comparison of process technologies for biochemical ethanol production from corn stover. Fuel 89, Supplement 1(0): S20-S28.

Kelloway, A. and P. Daoutidis (2013). Process Synthesis of Biorefineries: Optimization of Biomass Conversion to Fuels and Chemicals. Industrial \& Engineering Chemistry Research 53(13): 52615273.

Kim, J., S. M. Sen and C. T. Maravelias (2013). An optimization-based assessment framework for biomass-to-fuel conversion strategies. Energy \& Environmental Science 6(4): 1093-1104.

Klein-Marcuschamer, D., P. Oleskowicz-Popiel, B. A. Simmons and H. W. Blanch (2010). Technoeconomic analysis of biofuels: A wiki-based platform for lignocellulosic biorefineries. Biomass and Bioenergy 34(12): 1914-1921.

Klein-Marcuschamer, D., B. A. Simmons and H. W. Blanch (2011). Techno-economic analysis of a lignocellulosic ethanol biorefinery with ionic liquid pre-treatment. Biofuels, Bioproducts and Biorefining 5(5): 562-569.

Kokossis, A. C. and A. Yang (2010). On the use of systems technologies and a systematic approach for the synthesis and the design of future biorefineries. Computers \& Chemical Engineering 34(9): 13971405.

Lange, J.-P. (2007). Lignocellulose conversion: an introduction to chemistry, process and economics. Biofuels, Bioproducts and Biorefining 1(1): 39-48.

Lau, M. W. and B. E. Dale (2009). Cellulosic ethanol production from AFEX-treated corn stover using Saccharomyces cerevisiae 424A(LNH-ST). Proceedings of the National Academy of Sciences 106(5): 1368-1373.

Lozowski, D. (2012). Economic indicators. Chemical Engineering 119(1): 56-57.

Luterbacher, J. S., J. M. Rand, D. M. Alonso, J. Han, J. T. Youngquist, C. T. Maravelias, B. F. Pfleger and J. A. Dumesic (2014). Nonenzymatic Sugar Production from Biomass Using Biomass-Derived $\gamma$ Valerolactone. Science 343(6168): 277-280.

Martín, M. and I. E. Grossmann (2011). Process Optimization of FT-Diesel Production from Lignocellulosic Switchgrass. Industrial \& Engineering Chemistry Research 50(23): 13485-13499.

Mohan, D., C. U. Pittman and P. H. Steele (2006). Pyrolysis of Wood/Biomass for Bio-oil: A Critical Review. Energy \& Fuels 20(3): 848-889.

Mosier, N., C. Wyman, B. Dale, R. Elander, Y. Y. Lee, M. Holtzapple and M. Ladisch (2005). Features of promising technologies for pretreatment of lignocellulosic biomass. Bioresource Technology 96(6): 673-686.

Naik, S. N., V. V. Goud, P. K. Rout and A. K. Dalai (2010). Production of first and second generation biofuels: A comprehensive review. Renewable and Sustainable Energy Reviews 14(2): 578-597.

Pham, V. and M. El-Halwagi (2012). Process synthesis and optimization of biorefinery configurations. AlChE Journal 58(4): 1212-1221. 
Pokoo-Aikins, G., A. Nadim, M. M. El-Halwagi and V. Mahalec (2010). Design and analysis of biodiesel production from algae grown through carbon sequestration. Clean Technologies and Environmental Policy 12(3): 239-254.

Sammons Jr, N. E., W. Yuan, M. R. Eden, B. Aksoy and H. T. Cullinan (2008). Optimal biorefinery product allocation by combining process and economic modeling. Chemical Engineering Research and Design 86(7): 800-808.

Sen, S. M., D. M. Alonso, S. G. Wettstein, E. I. Gurbuz, C. A. Henao, J. A. Dumesic and C. T. Maravelias (2012a). A sulfuric acid management strategy for the production of liquid hydrocarbon fuels via catalytic conversion of biomass-derived levulinic acid. Energy \& Environmental Science 5(12): 9690-9697.

Sen, S. M., D. M. Alonso, S. G. Wettstein, E. I. Gurbuz, C. A. Henao, J. A. Dumesic and C. T. Maravelias (2012a). A sulfuric acid management strategy for the production of liquid hydrocarbon fuels via catalytic conversion of biomass-derived levulinic acid. Energy \& Environmental Science 5(12): 9690-9697.

Sen, S. M., J. B. Binder, R. T. Raines and C. T. Maravelias (2012b). Conversion of biomass to sugars via ionic liquid hydrolysis: process synthesis and economic evaluation. Biofuels, Bioproducts and Biorefining 6(4): 444-452.

Sen, S. M., E. I. Gurbuz, S. G. Wettstein, D. M. Alonso, J. A. Dumesic and C. T. Maravelias (2012b). Production of butene oligomers as transportation fuels using butene for esterification of levulinic acid from lignocellulosic biomass: process synthesis and technoeconomic evaluation. Green Chemistry 14(12): 3289-3294.

Sen, S. M., E. I. Gurbuz, S. G. Wettstein, D. M. Alonso, J. A. Dumesic and C. T. Maravelias (2012c). Production of butene oligomers as transportation fuels using butene for esterification of levulinic acid from lignocellulosic biomass: process synthesis and technoeconomic evaluation. Green Chemistry 14(12): 3289-3294.

Sen, S. M., C. A. Henao, D. J. Braden, J. A. Dumesic and C. T. Maravelias (2012c). Catalytic conversion of lignocellulosic biomass to fuels: Process development and technoeconomic evaluation. Chemical Engineering Science 67(1): 57-67.

Sen, S. M., C. A. Henao, D. J. Braden, J. A. Dumesic and C. T. Maravelias (2012d). Catalytic conversion of lignocellulosic biomass to fuels: Process development and technoeconomic evaluation. Chemical Engineering Science 67(1): 57-67.

Sendich, E., M. Laser, S. Kim, H. Alizadeh, L. Laureano-Perez, B. Dale and L. Lynd (2008). Recent process improvements for the ammonia fiber expansion (AFEX) process and resulting reductions in minimum ethanol selling price. Bioresource Technology 99(17): 8429-8435.

Serrano-Ruiz, J. C., D. J. Braden, R. M. West and J. A. Dumesic (2010). Conversion of cellulose to hydrocarbon fuels by progressive removal of oxygen. Applied Catalysis B: Environmental 100(12): 184-189.

Stuart, P. R. and M. M. El-Halwagi (2012). Integrated biorefineries: design, analysis, and optimization, CRC Press.

Swanson, R. M., A. Platon, J. A. Satrio and R. C. Brown (2010). Techno-economic analysis of biomass-toliquids production based on gasification. Fuel 89, Supplement 1(0): S11-S19.

Tao, L., A. Aden, R. T. Elander, V. R. Pallapolu, Y. Y. Lee, R. J. Garlock, V. Balan, B. E. Dale, Y. Kim, N. S. Mosier, M. R. Ladisch, M. Falls, M. T. Holtzapple, R. Sierra, J. Shi, M. A. Ebrik, T. Redmond, B. Yang, C. E. Wyman, B. Hames, S. Thomas and R. E. Warner (2011). Process and technoeconomic analysis of leading pretreatment technologies for lignocellulosic ethanol production using switchgrass. Bioresource Technology 102(24): 11105-11114.

U.S.EIA (2012). Levelized Cost of New Generation Resources in the Annual Energy Outlook 2011. 
Wettstein, S. G., D. M. Alonso, E. I. Gürbüz and J. A. Dumesic (2012). A roadmap for conversion of lignocellulosic biomass to chemicals and fuels. Current Opinion in Chemical Engineering 1(3): 218-224.

Wright, M. M., D. E. Daugaard, J. A. Satrio and R. C. Brown (2010). Techno-economic analysis of biomass fast pyrolysis to transportation fuels. Fuel 89, Supplement 1(0): S2-S10.

You, F., L. Tao, D. J. Graziano and S. W. Snyder (2012). Optimal design of sustainable cellulosic biofuel supply chains: Multiobjective optimization coupled with life cycle assessment and input-output analysis. AlChE Journal 58(4): 1157-1180.

Yuan, Z., B. Chen and R. Gani (2013). Applications of process synthesis: Moving from conventional chemical processes towards biorefinery processes. Computers \& Chemical Engineering 49(0): 217-229. 